Article

\title{
Synthesis of Silica Membranes by Chemical Vapor Deposition Using a Dimethyldimethoxysilane Precursor
}

\author{
S. Ted Oyama ${ }^{1,2,3, * \mathbb{C}}$, Haruki Aono ${ }^{2}$, Atsushi Takagaki ${ }^{2,4} \mathbb{D}$, Takashi Sugawara ${ }^{2}$ and \\ Ryuji Kikuchi ${ }^{2}$ \\ 1 College of Chemical Engineering, Fuzhou University, Fuzhou 350116, China \\ 2 Department of Chemical Systems Engineering, The University of Tokyo, 7-3-1 Hongo, Bunkyo-ku, \\ Tokyo 113-8656, Japan; aaa.ooo.nnn.ooo@gmail.com (H.A.); atakagak@cstf.kyushu-u.ac.jp (A.T.); \\ sugawara@chemsys.t.u-tokyo.ac.jp (T.S.); rkikuchi@chemsys.t.u-tokyo.ac.jp (R.K.) \\ 3 Department of Chemical Engineering, Virginia Tech, Blacksburg, VA 24061, USA \\ 4 Present address: Department of Applied Chemistry, Faculty of Engineering, Kyushu University, \\ 744 Motooka, Nishi-ku, Fukuoka 819-0395, Japan \\ * Correspondence: oyama@vt.edu; Tel.: +81-3-3727-1254
}

Received: 19 February 2020; Accepted: 15 March 2020; Published: 22 March 2020

\begin{abstract}
Silica-based membranes prepared by chemical vapor deposition of tetraethylorthosilicate (TEOS) on $\gamma$-alumina overlayers are known to be effective for hydrogen separation and are attractive for membrane reactor applications for hydrogen-producing reactions. In this study, the synthesis of the membranes was improved by simplifying the deposition of the intermediate $\gamma$-alumina layers and by using the precursor, dimethyldimethoxysilane (DMDMOS). In the placement of the $\gamma$-alumina layers, earlier work in our laboratory employed four to five dipping-calcining cycles of boehmite sol precursors to produce high $\mathrm{H}_{2}$ selectivities, but this took considerable time. In the present study, only two cycles were needed, even for a macro-porous support, through the use of finer boehmite precursor particle sizes. Using the simplified fabrication process, silica-alumina composite membranes with $\mathrm{H}_{2}$ permeance $>10^{-7} \mathrm{~mol} \mathrm{~m}^{-2} \mathrm{~s}^{-1} \mathrm{~Pa}^{-1}$ and $\mathrm{H}_{2} / \mathrm{N}_{2}$ selectivity $>100$ were successfully synthesized. In addition, the use of the silica precursor, DMDMOS, further improved the $\mathrm{H}_{2}$ permeance without compromising the $\mathrm{H}_{2} / \mathrm{N}_{2}$ selectivity. Pure DMDMOS membranes proved to be unstable against hydrothermal conditions, but the addition of aluminum tri-sec-butoxide (ATSB) improved the stability just like for conventional TEOS membranes.
\end{abstract}

Keywords: silica-alumina membrane; dimethyldimethoxysilane (DMDMOS); hydrothermal stability; chemical vapor deposition; gamma-alumina intermediate layers; hydrogen helium separation

\section{Introduction}

Silica-based membranes have been known to be effective for selective hydrogen permeation for more than 30 years, and are potentially less expensive than palladium-based membranes. The subject of silica membranes has been covered in recent reviews [1-3] and several recent papers [4-8]. Notable past work includes the original papers [9,10], the use of sol-gel techniques [11,12], chemical vapor deposition (CVD) $[13,14]$ and plasma methods [15,16], the employment of diverse CVD precursors [17-21] and compositions [22-24], the determination of porosity [25], and the elucidation of the mechanism of permeation [26-28]. Important precedents are the use of dimethyldimethoxysilane (DMDMOS) [17] and other methyl-substituted siloxanes [29,30].

The separation mechanism of small species like $\mathrm{He}, \mathrm{H}_{2}$, and $\mathrm{Ne}$ in silica membranes prepared by chemical vapor deposition of alkoxide substrates is based on molecular hopping between solubility 
sites [31]. The sites in the silica network are approximately $0.3 \mathrm{~nm}$, allowing only small gas molecules like $\mathrm{He}, \mathrm{H}_{2}$, or $\mathrm{Ne}$ to enter them [31,32]. The only way for larger gas molecules to permeate is to pass through pores or defects such as pinholes or cracks. Therefore, the avoidance of defects is important for high $\mathrm{H}_{2}$ selectivity, and this will be one of the topics covered in this study. Permeance in membranes with larger pores may occur by a modified gas translational mechanism [33].

Usually, the sol-gel cycle in the synthesis of intermediate layers must be repeated several times to ensure a defect-free membrane [34]. However, too many repetitions not only require longer preparation time with extra energy consumption, but also increase the $\gamma$-alumina thickness, thereby posing the risk of cracking. Particularly, a previous study [35] achieved very high $\mathrm{H}_{2}$ permeance and selectivity by applying four to five dipping-calcining cycles to form a graded $\gamma$-alumina intermediate layer on a macro-porous support, but this was time-consuming and undesirable for reproducibility and cost reasons. It is desirable to reduce the required number of dipping-calcining cycles for a specific membrane support, and this will be one of the topics covered in this study. Scanning electron microscopy (SEM) is used to image samples at intermediate stages of synthesis so as to provide insight on the difference between successful and failed membranes. In addition, the $\mathrm{H}_{2}$ permeance is further improved by using a novel silica precursor compound, dimethyldimethoxysilane [17], which makes the silica network slightly looser.

A potential use of silica membranes is in membrane reactors [36-40], so a significant concern is the stability under thermal or hydrothermal conditions [41-43]. Particularly, exposure to water vapor at an elevated temperature quickly leads to deterioration of the membrane performance. In general, the $\mathrm{H}_{2}$ permeance will decrease due to the densification of the silica network, and the permeance of larger gas molecules will increase due to pinhole generation caused by the degradation of $\gamma$-alumina, when it is used as a support. This was confirmed by Reference [17], where hydrothermal stability tests were conducted on both the inside and outside of the membrane tube. The densification of the silica is believed to occur due to the hydrolysis of Si-O-Si linkages and the formation of Si-OH hydroxyl groups, and the degradation of the $\gamma$-alumina is believed to occur due to sintering and pore enlargement.

To improve the stability of the silica layer metal elements such as $\mathrm{Al}[44,45]$ or $\mathrm{Ti}[46]$ can be incorporated into the Si network. They are thought to impart higher tolerance against the attack of the $\mathrm{H}_{2} \mathrm{O}$ molecules to the Si-O-Si bond. For example, in the case of a silica-alumina composite membrane [44], the initial $\mathrm{H}_{2}$ permeance was $2-3 \times 10^{-7} \mathrm{~mol} \mathrm{~m}^{-2} \mathrm{~s}^{-1} \mathrm{~Pa}^{-1}$ with a $\mathrm{H}_{2} / \mathrm{CH}_{4}$ selectivity of 940 at $600{ }^{\circ} \mathrm{C}$, and the $\mathrm{H}_{2}$ permeance was maintained above $10^{-7} \mathrm{~mol} \mathrm{~m}^{-2} \mathrm{~s}^{-1} \mathrm{~Pa}^{-1}$ even after exposure to $16 \mathrm{~mol} \%$ steam for $500 \mathrm{~h}$ at $600{ }^{\circ} \mathrm{C}$. In the case of a silica-titania composite membrane [46], the initial $\mathrm{H}_{2}$ permeance was $3 \times 10^{-7} \mathrm{~mol} \mathrm{~m}^{-2} \mathrm{~s}^{-1} \mathrm{~Pa}^{-1}$ and was reduced by only $30 \%$ after $130 \mathrm{~h}$ of exposure in $75 \mathrm{~mol} \% \mathrm{H}_{2} \mathrm{O}$ at $650{ }^{\circ} \mathrm{C}$, though the $\mathrm{H}_{2} / \mathrm{CH}_{4}$ selectivity was at moderate level (40-60). The above-mentioned membranes are much more stable than pure silica membranes, where a reduction of more than $90 \%$ of the $\mathrm{H}_{2}$ permeance is typical $[47,48]$. In this study, silica-alumina composite membranes are employed for hydrothermal stability.

The stability of $\gamma$-alumina can also be improved by metal-doping. Silica membranes fabricated by counter diffusion chemical vapor deposition (CVD) of tetramethoxyorthosilicate (TMOS)/O $\mathrm{O}_{2}$ on pure or Ni-doped $\gamma$-alumina showed hydrothermal stability at $500{ }^{\circ} \mathrm{C}$ with a steam/ $\mathrm{N}_{2}$ ratio of 3 [49]. The authors pointed out that for the membrane with pure $\gamma$-alumina, the $\mathrm{N}_{2}$ permeance fluctuated during the hydrothermal exposure and significantly increased from the initial value, but by doping $5 \mathrm{~mol} \% \mathrm{Ni}$ into the $\gamma$-alumina, the problem was minimized. The actual stabilization mechanism, however, was not clarified in the paper. Subsequent work [41] discussed the membrane degradation mechanism in detail, and attributed the fluctuation of the $\mathrm{N}_{2}$ permeance to the combination of $\gamma$-alumina pore enlargement, pore plugging by grain growth, and subsequent grain rearrangement.

To achieve a high $\mathrm{H}_{2}$ permeance without affecting the $\mathrm{H}_{2}$ selectivity against the target compound to be separated, it is important to strictly control the pore size of the silica network. Silica membranes fabricated by counter diffusion CVD of TMOS, and one-sided diffusion CVD of phenyltrimethoxysilane (PTMS) and dimethoxydiphenylsilane (DMDPS) have been investigated [50]. The use of DMDPS 
resulted in a $\mathrm{H}_{2}$ permeance of the order of $10^{-6} \mathrm{~mol} \mathrm{~m}^{-2} \mathrm{~s}^{-1} \mathrm{~Pa}^{-1}$ and a $\mathrm{H}_{2} / \mathrm{SF}_{6}$ selectivity of 6800 at $300{ }^{\circ} \mathrm{C}$, which is comparable to the performance of palladium membranes. Subsequent work [51,52] using this membrane confirmed that the $\mathrm{H}_{2} /$ toluene separation ability was stable for more than $1000 \mathrm{~h}$. It should be noted, however, that the $\mathrm{H}_{2} / \mathrm{N}_{2}$ selectivity was lower than $\sim 100$ due to an open porous silica network (0.3-0.47 nm [51]) compared to the TEOS- or TMOS-derived networks ( 0.3 nm). Several studies have focused on silica membranes with other functional groups like vinyltriethoxysilane [53]. Noteworthy are recent studies that describe high-performance silica membranes [54-56].

Silica membranes prepared by counter diffusion CVD have also been studied using a number of silica precursors [57]. Among them, the use of DMDMOS resulted in a superior $\mathrm{H}_{2}$ permeance of $9.0 \times 10^{-7} \mathrm{~mol} \mathrm{~m}^{-2} \mathrm{~s}^{-1} \mathrm{~Pa}^{-1}$ and $\mathrm{H}_{2} / \mathrm{N}_{2}$ selectivity of 920 at $500{ }^{\circ} \mathrm{C}$. However, the paper [17] did not report detailed information about long-term stability or the gas permeation mechanism of the new membrane, so these will be covered in this study.

\section{Materials and Methods}

\subsection{Materials}

The membranes used in this research consisted of three layers: a commercial $\alpha$-alumina support (Noritake Co.) with nominal pore size of $60 \mathrm{~nm}$, a $\gamma$-alumina intermediate layer deposited by sequential dip-coating/calcining, and a topmost silica layer placed by chemical vapor deposition (CVD). Before silica deposition, two membranes were synthesized in parallel under the same conditions (Figure 1). Then, one membrane was used for CVD and the other membrane was used for scanning electron microscopy (SEM) analysis to have identical substrates for clarifying the relationship between the surface or cross-sectional morphology and the gas separation ability.

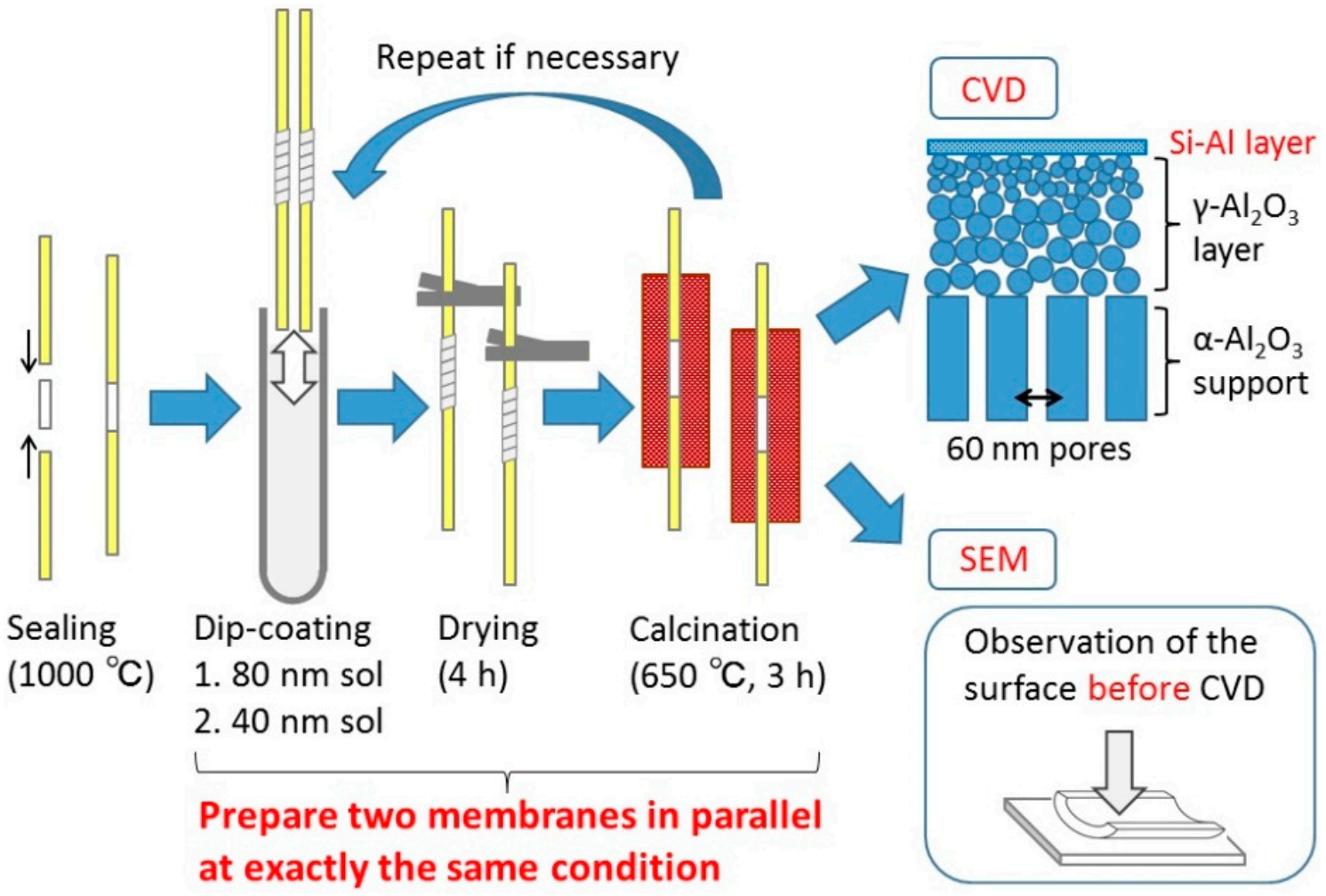

Figure 1. Membrane fabrication procedures. CVD-Chemical vapor deposition, SEM-Scanning electron microscopy. 


\subsection{Membrane Fabrication}

\subsubsection{Preparation of the Dipping Sols}

The $\gamma$-alumina layers were prepared by sol-gel coating of boehmite sols, which were synthesized through the hydrolysis of aluminum isopropoxide (Aldrich, $>98 \%$ ) and subsequent peptization by nitric acid, as reported previously [58]. The boehmite particle sizes were controlled by the time of hydrolysis and the amount of nitric acid. The actual dipping solutions were prepared by mixing the boehmite sols with a polyvinyl alcohol (PVA, Polysciences, M.W. $=\sim 78,000$ ) solution to minimize the risk of cracking by slightly raising the sol viscosity. The obtained concentration of the sol and PVA were 0.15 wt. $\%$ and 0.35 wt. $\%$, respectively.

\subsubsection{Preparation of the Intermediate Layers}

First, a commercial $\alpha$-alumina tube (i.d. $=4 \mathrm{~mm}$, o.d. $=6 \mathrm{~mm}$, length $=30 \mathrm{~mm}$ ) with $60 \mathrm{~nm}$ pores (Noritake Corporation) was connected to non-porous alumina tubes (i.d. $=4 \mathrm{~mm}$, o.d. $=6 \mathrm{~mm}$, length $=200 \mathrm{~mm}$ ) at both ends with ceramic joints, which were made by applying a glass paste and firing at $1000^{\circ} \mathrm{C}$. Second, the tube was dipped into the dipping solution for $10 \mathrm{~s}$ with its outer surface wrapped with Teflon tape. Third, the tube was dried in a laminar flow enclosure with high efficiency particulate air filters for $4 \mathrm{~h}$, and was calcined at $650{ }^{\circ} \mathrm{C}$ for $3 \mathrm{~h}$. Here, a relatively slow heating/cooling rate of $1.5^{\circ} \mathrm{C} / \mathrm{min}$ was applied in order to minimize the risk of cracking due to different thermal expansion coefficients between the support and the intermediate layer. The dipping-calcining cycle was repeated as necessary.

\subsubsection{Preparation of the Topmost Silica Layers}

The topmost silica layers were synthesized by chemical vapor deposition (CVD), which placed a thin $(20 \sim 30 \mathrm{~nm})$ silica layer on top of the $\gamma$-alumina substrate by the thermal decomposition of the silica precursor compound. First, a conventional silica precursor, tetraethyl orthosilicate (TEOS) (Aldrich, $98 \%$ ), was used to concentrate on the optimization of the intermediate layer. The schematic diagram of the CVD apparatus is shown in Figure 2a. The $6 \mathrm{~mm}$ diameter support tube was coaxially fixed inside the stainless reactor using machined Swagelok fittings with Teflon ferrules. The assembly was placed in an electric furnace and was heated to $650{ }^{\circ} \mathrm{C}$ at a heating rate of $1.5^{\circ} \mathrm{C} / \mathrm{min}$. The bubbler temperature for the TEOS delivery was kept at $25^{\circ} \mathrm{C}$, which gave a TEOS vapor pressure of $250 \mathrm{~Pa}$ (obtained from the following Antoine equation).

$$
\log _{10} P=A-\frac{B}{T+C}, A=4.17312, B=1561.277, C=-67.572, P[\mathrm{bar}], T[\mathrm{~K}]
$$

To improve the hydrothermal stability, a silica-alumina composite membrane was fabricated using a second bubbler to deliver aluminum tri-sec-butoxide (ATSB) as a secondary component in addition to the TEOS (Figure 1a). In this case, the bubbler temperature for the ATSB delivery was set at $96{ }^{\circ} \mathrm{C}$ so that the $\mathrm{Al} / \mathrm{Si}$ ratio would be 0.03 . This value was determined by considering the tradeoff between the hydrothermal stability and the $\mathrm{H}_{2}$ selectivity obtained in a previous study [44]. The two carrier gases were premixed with a dilution Ar gas before introduction to the inside of the support tube. The lines leading to the inner tube were heated by a ribbon heater to prevent condensation of the precursor compounds. A balance argon gas was also introduced to the outer shell in order to maintain pressure balance between inside and outside of the support tube and minimize the loss of $\mathrm{H}_{2}$ permeance due to silica deposition within the pores of the $\gamma$-alumina. After the CVD process was finished, the assembly was purged with the balance and dilution Ar gases for about 15 min to sweep out any unreacted precursor compounds or reaction byproducts.

To further improve the $\mathrm{H}_{2}$ permeance without compromising the $\mathrm{H}_{2}$ selectivity, a novel silica precursor reported in the literature, dimethyldimethoxysilane (DMDMOS) [17], was also examined. The reported $\mathrm{H}_{2}$ permeance and $\mathrm{H}_{2} / \mathrm{N}_{2}$ selectivity were $9.0 \times 10^{-7} \mathrm{~mol} \mathrm{~m}^{-2} \mathrm{~s}^{-1} \mathrm{~Pa}^{-1}$ and 920 , respectively, 
but the authors did not describe any detailed information about the gas permeation mechanism or the long-term stability of the membrane. Therefore, these will be investigated in this study.

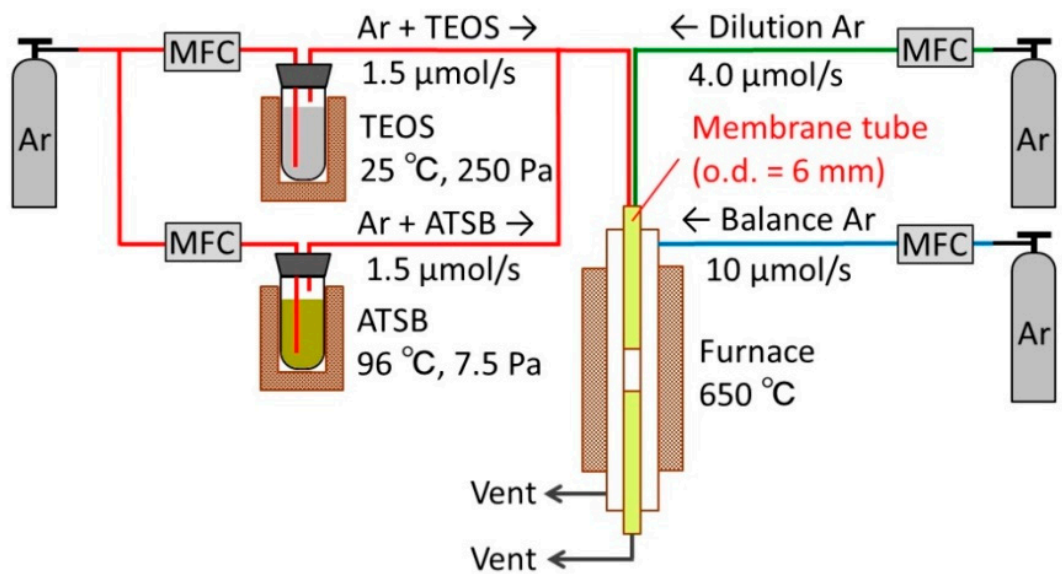

(a)

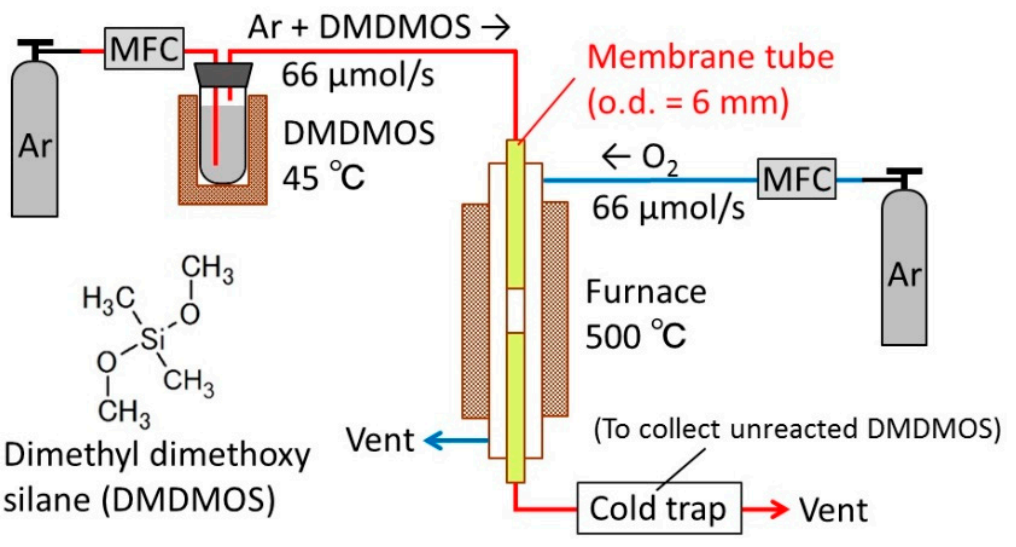

(b)

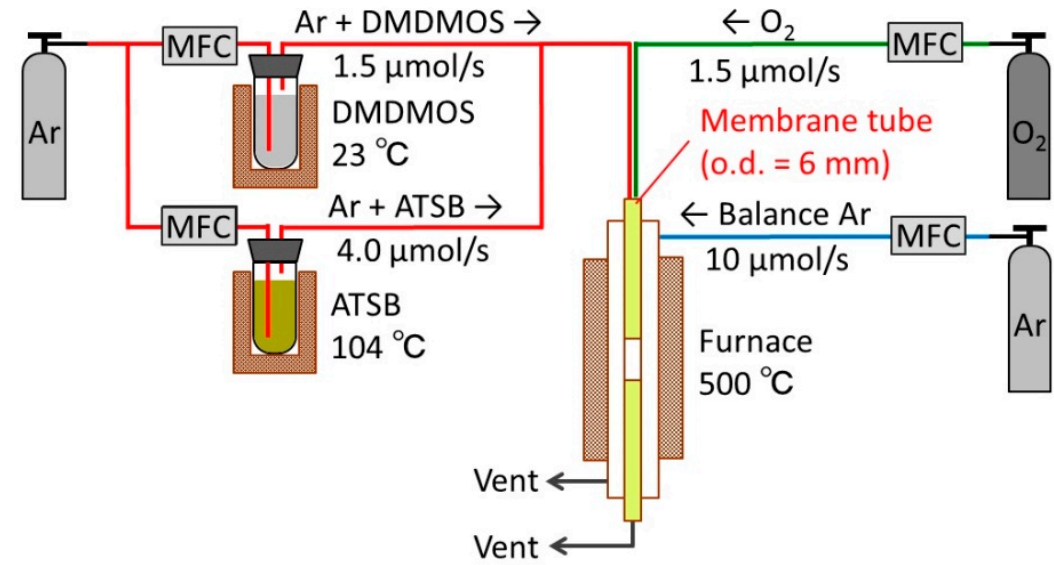

(c)

Figure 2. Experimental setup for several types of chemical vapor deposition (CVD). (a) One-sided diffusion CVD of tetraethylorthosilicate (TEOS)/aluminum tri-sec-butoxide (ATSB), (b) counter-diffusion CVD of dimethyldimethoxysilane (DMDMOS)/ $\mathrm{O}_{2}$, (c) one-side diffusion CVD of DMDMOS/ATSB $/ \mathrm{O}_{2}$. 
To synthesize DMDMOS membranes, both counter-diffusion CVD (Figure $2 b$ ) and one-sided diffusion CVD (Figure 2c) were applied, whereas the previous study [17] dealt with only counter-diffusion CVD. Particularly, the one-sided diffusion CVD made it easier to add the stream of ATSB to improve the hydrothermal stability. In both cases, the CVD temperature was set at $500{ }^{\circ} \mathrm{C}$ in order to prevent support cracking due to the large reaction heat between DMDMOS and $\mathrm{O}_{2}$ in accordance with the previous report [17].

\subsection{Evaluation of the As-Synthesized Membranes}

\subsubsection{SEM Analysis}

The surface and cross-sectional microstructures of the membranes were studied using field emission scanning electron microscopy (FESEM, S-900, Tokyo, Japan). Samples were obtained by mechanically slicing the tubular membranes with a diamond saw and subsequently chopping the sliced discs with a cutter. The samples were sputtered with platinum for $15 \mathrm{~s}$ before the measurements with SEM. Through the observation, the following points were examined (Table 1).

Table 1. Characterization of Membranes by Scanning Electron Microscopy.

\begin{tabular}{|c|c|c|}
\hline & Samples before CVD & Samples after CVD \\
\hline Surface & $\begin{array}{c}\text { Particle size of } \gamma \text {-alumina } \\
\cdot \quad \text { Porosity } \\
\cdot \quad \text { Smoothness } \\
\cdot \quad \text { Presence of pinholes }\end{array}$ & $\begin{array}{l}\text { Smoothness } \\
\text { Presence of pinholes }\end{array}$ \\
\hline Cross-section & $\begin{array}{l}\text { Thickness of the } \gamma \text {-alumina layer } \\
\text { Presence of } \gamma \text {-alumina particle } \\
\text { infiltration into } \alpha \text {-alumina } \\
\text {. Presence of cracks }\end{array}$ & $\begin{array}{c}\text {. Thickness of the silica layer } \\
\text {. Presence of silica infiltration } \\
\cdot \quad \text { into } \gamma \text {-alumina } \\
\text {. Presence of cracks }\end{array}$ \\
\hline
\end{tabular}

\subsubsection{Single Gas Permeation Test}

The CVD process was interrupted at various deposition times, and gas permeation tests were carried out at $650{ }^{\circ} \mathrm{C}$ using the same apparatus. The sample gases $\left(\mathrm{H}_{2}, \mathrm{He}, \mathrm{Ne}, \mathrm{N}_{2}, \mathrm{CO}_{2}, \mathrm{Ar}\right)$ were introduced into the inside of the membrane tube, the bottom end of which was closed. Then, the gas permeation rates from the outer shell were measured either by a flow meter or a gas chromatograph. Permeances were calculated using the following equation:

$$
\bar{P}=\frac{F}{A \Delta p}
$$

where $\bar{P}$ is the permeance $\left(\mathrm{mol} \mathrm{m}{ }^{-2} \mathrm{~s}^{-1} \mathrm{~Pa}^{-1}\right), F$ is the molar flow rate $\left(\mathrm{mol} \mathrm{s}^{-1}\right), A$ is the permeation area $\left(\mathrm{m}^{2}\right)$, and $\Delta p$ is the pressure difference across the membrane (Pa). The permeation area, $A$, was calculated by:

$$
A=\frac{\pi L\left(r_{1}-r_{2}\right)}{\ln \left(\frac{r_{1}}{r_{2}}\right)}
$$

where $L$ is the effective membrane length, $r_{1}$ is the outer diameter, and $r_{2}$ is the inner diameter. The ideal selectivity was defined as the ratio of the single gas permeances:

$$
\alpha_{i j}=\frac{\bar{P}_{i}}{\bar{P}_{j}}
$$

where $\alpha_{i j}$ is the selectivity of gas $i$ versus $j, \bar{P}_{i}$ is the permeance of gas $i\left(\mathrm{~mol} \mathrm{~m}^{-2} \mathrm{~s}^{-1} \mathrm{~Pa}^{-1}\right)$, and $\bar{P}_{j}$ is the permeance of gas $j\left(\mathrm{~mol} \mathrm{~m}{ }^{-2} \mathrm{~s}^{-1} \mathrm{~Pa}^{-1}\right)$. For permeances higher than $10^{-9} \mathrm{~mol} \mathrm{~m}^{-2} \mathrm{~s}^{-1} \mathrm{~Pa}^{-1}$, 
an electronic mass flow meter was used for the measurement, and for lower permeances, a Shimazu 8A gas chromatograph was employed. In the latter case, He gas at a known flow rate was also introduced to the outer shell in order to sweep the permeated molecules to the detector of the gas chromatograph. Then, the gas flow rate was calculated from the He flow rate and sample gas concentration, which was obtained from the average peak area and the calibration curve. The selectivity was calculated as the ratio of the single gas permeances of $\mathrm{H}_{2}$ to $\mathrm{N}_{2}, \mathrm{CO}_{2}$, or Ar.

\subsubsection{Hydrothermal Stability Test}

As was described in the introduction (Section 1), both the topmost selective layer and its support layer must be substantially stable under the operating conditions; otherwise, it is impossible to use the membrane in practical applications. However, there are limited numbers of publications dealing with hydrothermal stability tests on both sides of the membrane. Therefore, in this study, hydrothermal stability tests targeting both the silica and the $\gamma$-alumina layers were conducted at $650{ }^{\circ} \mathrm{C}$, up to $200 \mathrm{~h}$.

First, an Ar flow at $6.6 \mu \mathrm{mol} \mathrm{s}{ }^{-1}$ (flow rates in $\mu \mathrm{mol} \mathrm{s}{ }^{-1}$ can be converted into $\mathrm{ml}(\mathrm{NTP}) \mathrm{min}^{-1}$ by multiplying by 1.5) was passed through a heated bubbler containing distilled water and was then introduced to the inside of the membrane tube to directly contact the silica layer. The bubbler temperature was set at $56{ }^{\circ} \mathrm{C}$ so that the Ar stream would contain $16 \mathrm{~mol} \%$ water vapor. At the same time, another Ar flow at $11.6 \mu \mathrm{mol} \mathrm{s}{ }^{-1}$ was introduced to the outside of the membrane tube. Both sides of the membrane were kept at atmospheric pressure. The hydrothermal treatment was interrupted at several exposure times, and the permeances of $\mathrm{H}_{2}, \mathrm{He}$, and $\mathrm{N}_{2}$ were measured to monitor the changes in the membrane performance. To make the permeance measurements, the humidified Ar was changed to a pure Ar for about 20 min to dry the membranes. The wet Ar flow was resumed immediately after the permeance measurements. The cycle was repeated several times until the membrane performance became almost unchanged.

Next, the configuration was altered. An Ar flow at $11.6 \mu \mathrm{mol} \mathrm{s}^{-1}$ containing $16 \mathrm{~mol} \%$ water vapor was introduced to the outer shell to directly contact the $\gamma$-alumina layer, while another dry Ar stream at $6.6 \mu \mathrm{mol} \mathrm{s}^{-1}$ was introduced to the inner tube. The gas permeances were measured after several exposure times just like the previous case. Figure 3 summarizes the experimental procedures for the above-described hydrothermal stability tests. As a note, the lines for the delivery of humidified Ar were maintained above $100{ }^{\circ} \mathrm{C}$ using ribbon heaters to prevent condensation of water vapor.

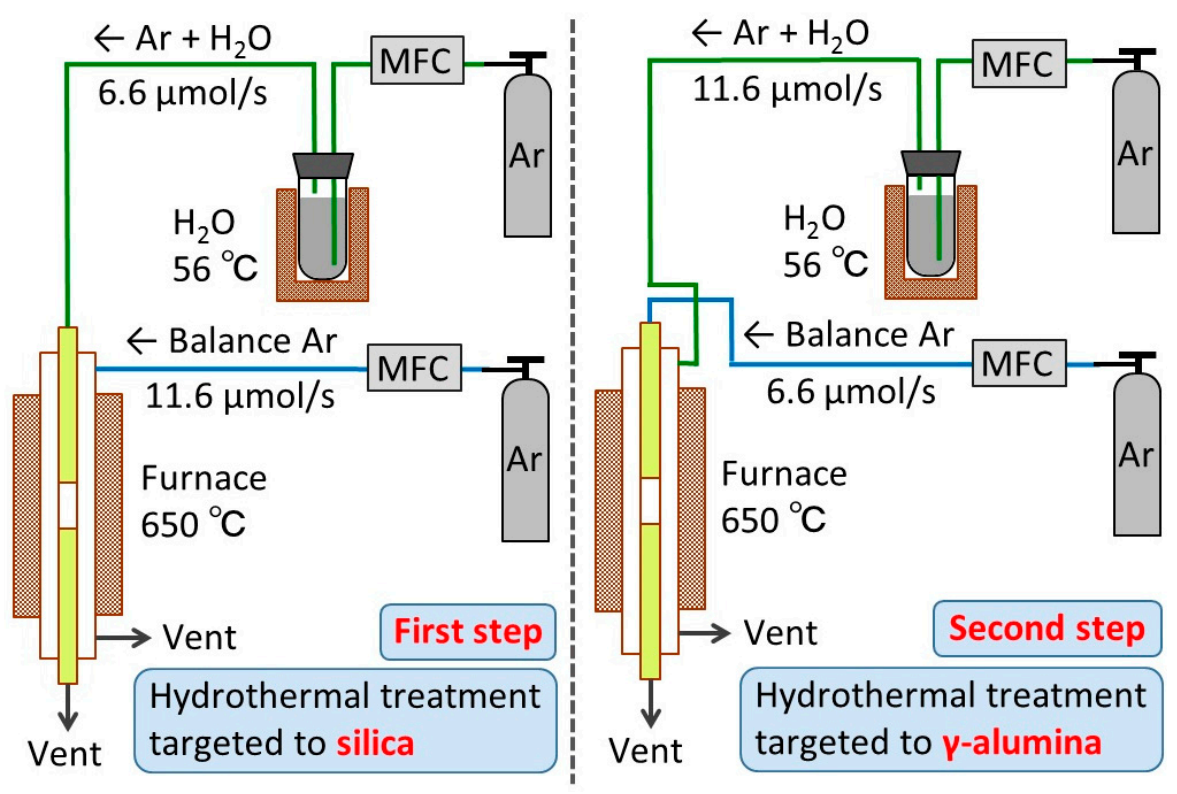

Figure 3. Hydrothermal stability test for both the inside and outside of the membrane tube. MFC-Mass flow controller. 


\section{Results and Discussion}

\subsection{Morphology and Structure of the Membranes}

Studies with scanning electron microscopy (SEM) revealed a progression of structure in the different membranes (Figure 4). The surface image of the $\alpha$-alumina support with nominal pore size of $60 \mathrm{~nm}$ (Figure 4a) treated once with a $200 \mathrm{~nm}$ sol shows that although a certain amount of $\gamma$-alumina was deposited on the $\alpha$-alumina, there were large areas of uncovered $\alpha$-alumina particles (Figure $4 b$ ). The image of the $\alpha$-alumina support treated by a $200 \mathrm{~nm}$ sol twice shows that the $\alpha$-alumina was totally covered by $\gamma$-alumina (Figure $4 c$ ). These results mean that at least two dipping-calcining cycles are required to eliminate large defects if large sols are used first. In addition, the support had a coarse surface and relatively large pores $(>5 \mathrm{~nm}$ ) (Figure $4 \mathrm{~d}$ ), so additional treatment with a smaller sol was necessary, thus bringing the total number of dipping-calcining cycles to three.

The $\gamma$-alumina surface prepared by dip-coating the $\alpha$-alumina support with a $40 \mathrm{~nm}$ sol (Figure $4 \mathrm{e}$ ) and 80 and $40 \mathrm{~nm}$ sols (Figure 4f) shows the successful formation of smooth and uniform $\gamma$-alumina layers. In addition, their cross-sectional images show that the thickness of the $\gamma$-alumina layer was about $1 \mu \mathrm{m}$ for the former (Figure $4 \mathrm{~g}$ ) and about $2 \mu \mathrm{m}$ for the latter (Figure $4 \mathrm{~h}$ ). These results suggest that macro-porous $\alpha$-alumina can be completely covered by $\gamma$-alumina even if the boehmite particle size is smaller than, or similar to, the support pore size. This has not been reported before.

To further investigate the microstructural differences between these two samples, pictures at higher magnification were taken (Figure 5). Careful observation reveals a slightly higher porosity for the sample with one treatment with $40 \mathrm{~nm}$ particles (Figure 5a) than that with successive 80 and $40 \mathrm{~nm}$ particles (Figure 5b). Then, the particle stacking density is slightly lower for the former. However, it was difficult to confirm a significant difference even with the nearly maximum resolution of SEM. Earlier studies [54-56] have demonstrated the usefulness of nanopermporometry in quantitating the pore size distribution of intermediate layers. Unfortunately, this was not undertaken in the present study. However, the microscopy does indicate that when only one intermediate layer was applied, the surface was only partly covered.

Although there were no clear differences between the samples before CVD, significant differences were found for the samples after CVD. For the sample with one layer of $40 \mathrm{~nm}$ sol, the formation of a silica layer was not complete and there were many visible pinhole defects (Figure $5 \mathrm{c}$ ), with those at the center of the picture being especially conspicuous. For the sample with successive layers of 80 and $40 \mathrm{~nm}$ sols, the surface was formed from continuous rounded structures, which is characteristic of a CVD-derived silica layer (Figure 5d) [59]. In addition, its cross-sectional image revealed that the thickness of the silica layer was about 30-40 nm (Figure 5e), which was similar to that in the previous study. These results clearly show that a smooth and uniform silica layer was successfully formed, although the dipping-calcining cycle was performed only twice on the macro-porous support. As a summary of all the above findings, at least two dipping-calcining cycles are necessary in order to obtain a pinhole-free membrane. 


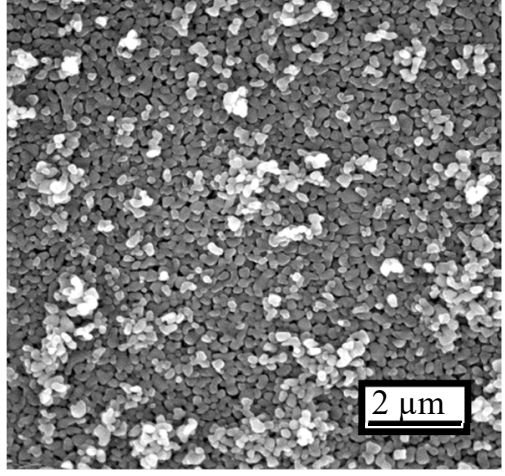

(a) Surface of the $\alpha$-alumina support with average pore size of $60 \mathrm{~nm}$

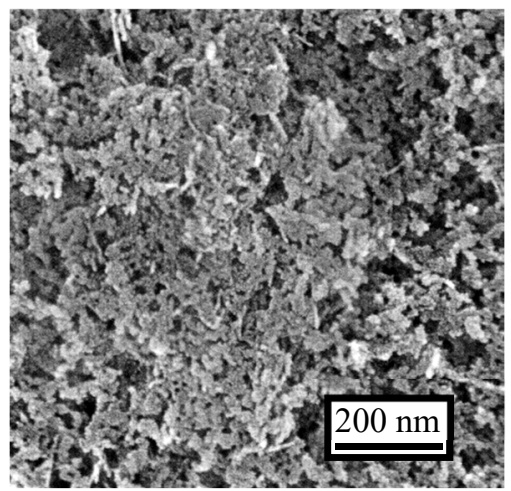

(d) Surface of the $60 \mathrm{~nm} \alpha$ alumina support treated twice with a $200 \mathrm{~nm}$ sol (high magnification)

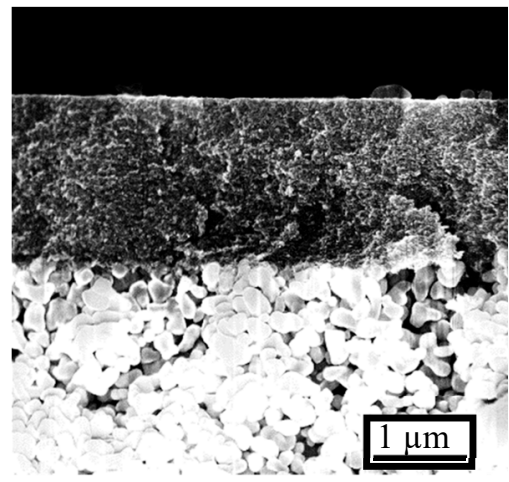

(g) Cross-section of the $60 \mathrm{~nm}$ $\alpha$-alumina support treated once with a $40 \mathrm{~nm}$ sol

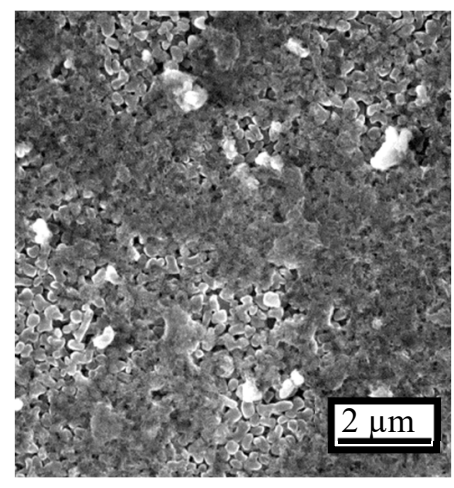

(b) Surface of the $60 \mathrm{~nm} \alpha$ alumina support treated once with a $200 \mathrm{~nm}$ sol

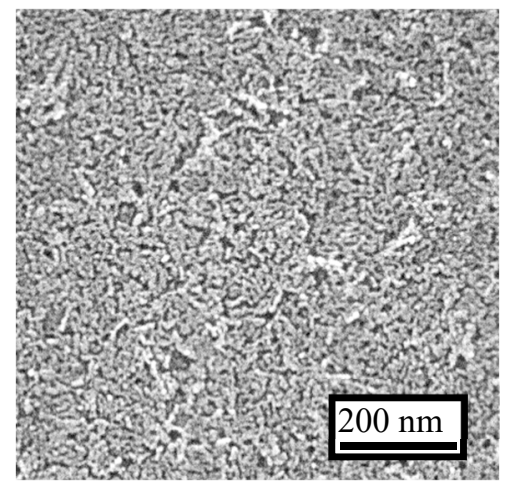

(e) Surface of the $60 \mathrm{~nm} \alpha$ alumina support treated once with a $40 \mathrm{~nm}$ sol (low magnification)

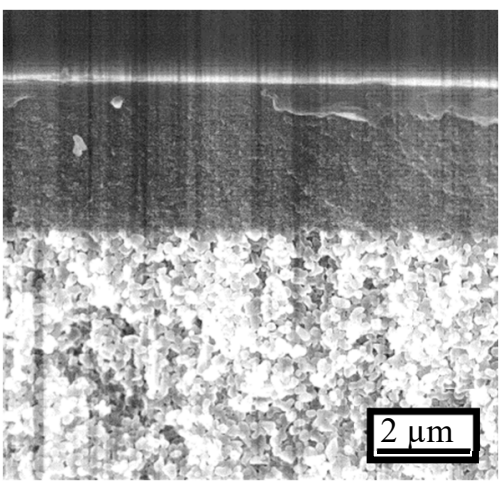

(h) Cross-section of the $60 \mathrm{~nm}$ $\alpha$-alumina support sequentially treated with an 80 $\mathrm{nm}$ sol and a $40 \mathrm{~nm}$ sol

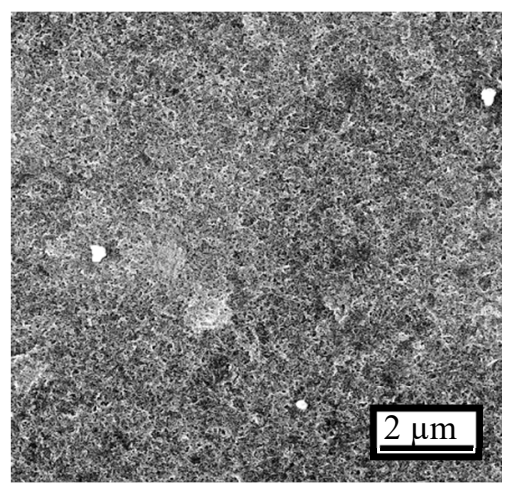

(c) Surface of the $60 \mathrm{~nm} \alpha$ alumina support treated twice with a $200 \mathrm{~nm}$ sol (low magnification)

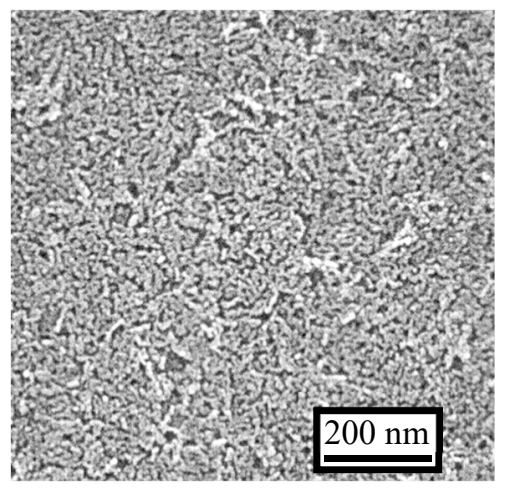

(f) Surface of the $60 \mathrm{~nm} \alpha$ alumina support treated with a $80 \mathrm{~nm}$ and a $40 \mathrm{~nm}$ sol (low magnification)

Figure 4. Scanning electron microscopy (SEM) images of the membranes at low magnification. 


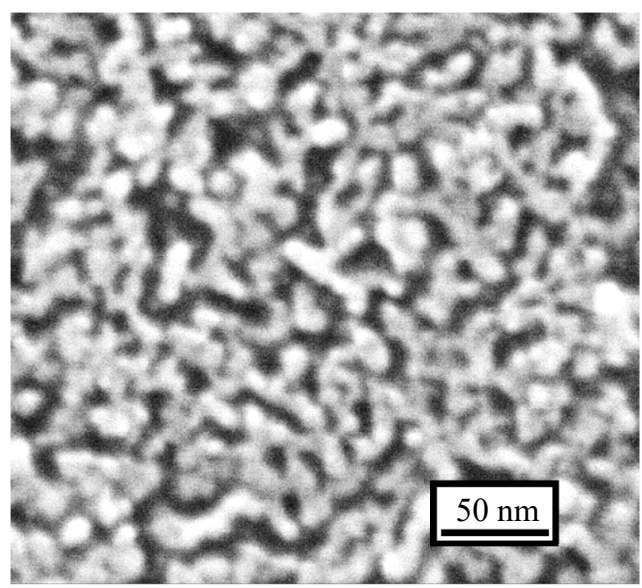

(a) Surface of the $60 \mathrm{~nm} \alpha$-alumina support treated once with a $40 \mathrm{~nm}$ sol (high magnification)

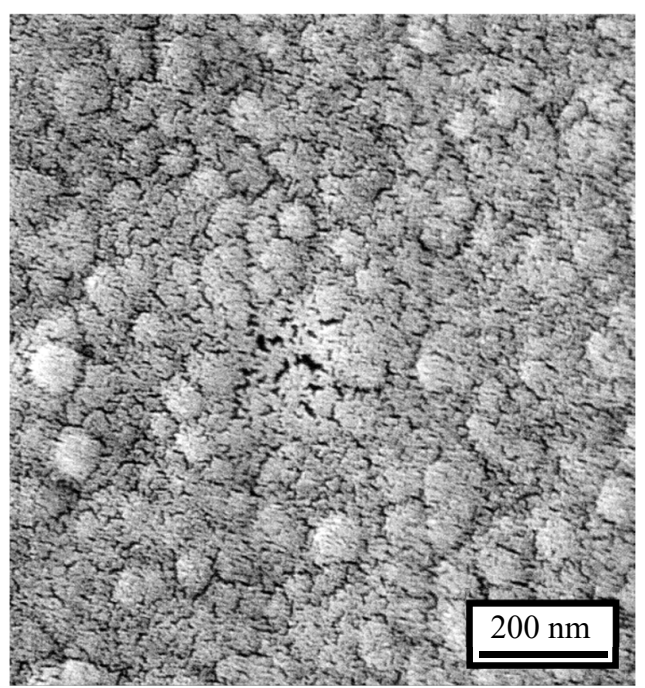

(c) Surface of the silica layer deposited on sample (a)

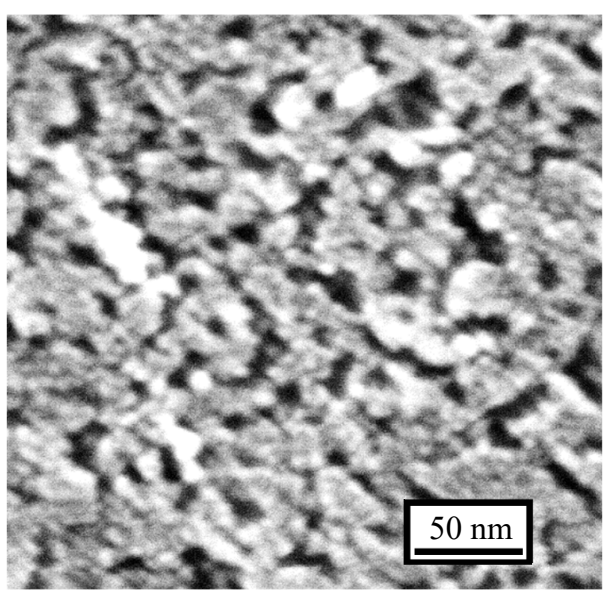

(b) Surface of the $60 \mathrm{~nm} \quad \alpha$-alumina support sequentially treated with an $80 \mathrm{~nm}$ sol and a $40 \mathrm{~nm}$ sol (high magnification)

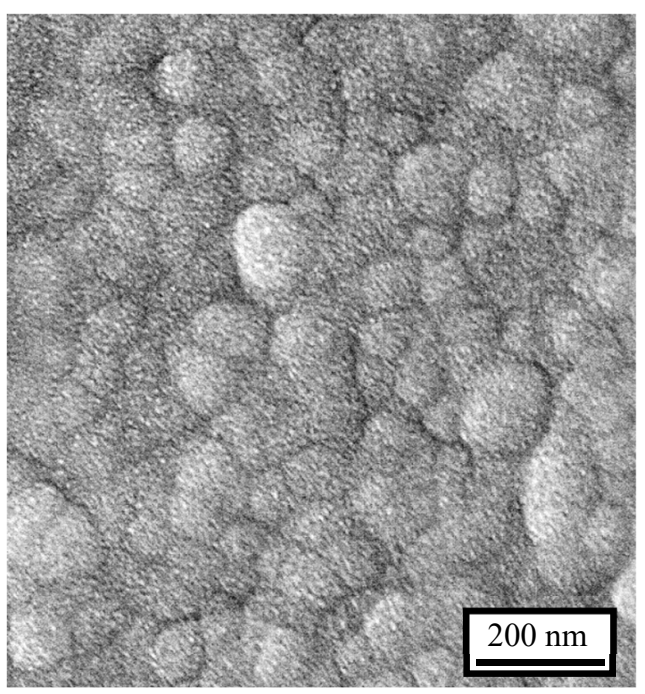

(d) Surface of the silica layer deposited on sample (b)

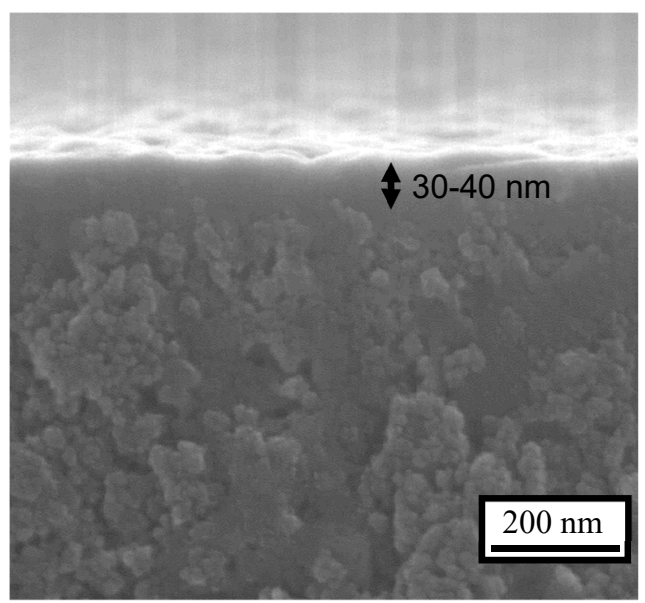

(e) Cross-section of the silica layer deposited on the $\gamma$-alumina layer

Figure 5. SEM images of the membranes at high magnification. 


\subsection{Gas Permeation Properties of the Membranes}

Figure 5 shows the changes in gas permeances during CVD for various types of membranes fabricated in this research. At the beginning of the study, a conventional silica precursor, TEOS, was applied to concentrate on the optimization of the intermediate layer. For the membrane with one treatment with a $40 \mathrm{~nm}$ sol, the $\mathrm{H}_{2}$ permeance at $650{ }^{\circ} \mathrm{C}$ was $1.2 \times 10^{-7} \mathrm{~mol} \mathrm{~m}^{-2} \mathrm{~s}^{-1} \mathrm{~Pa}^{-1}$ and the $\mathrm{H}_{2} / \mathrm{N}_{2}$ selectivity was 26 after $120 \mathrm{~min}$ of CVD (Figure 6a). This low selectivity is resonant with the defective surface structure revealed by SEM (Figure $5 \mathrm{c}$ ). On the other hand, for the membrane successively treated with $80 \mathrm{~nm}$ and $40 \mathrm{~nm}$ sols, the $\mathrm{H}_{2}$ permeance was the same $\left(1.2 \times 10^{-7} \mathrm{~mol} \mathrm{~m}^{-2} \mathrm{~s}^{-1} \mathrm{~Pa}^{-1}\right)$, but the $\mathrm{H}_{2} / \mathrm{N}_{2}$ selectivity was 330 after 90 min of CVD (Figure 6b). This result clearly demonstrated that a defect-free membrane (Figure $5 \mathrm{~d}$ ) can be synthesized with only two dipping-calcining cycles in spite of the use of a macro-porous $60 \mathrm{~nm} \alpha$-alumina support. Previous studies had used supports with substrate pores of $5 \mathrm{~nm}[28,35,44]$. Therefore, the repetition number of the dipping-calcining cycle was fixed at two for the subsequent studies.

Figure $6 \mathrm{c}$ shows the results for one of the successfully prepared membranes by the dual-element CVD of TEOS and ATSB. After 105 min of deposition, the $\mathrm{H}_{2}$ permeance and the $\mathrm{H}_{2} / \mathrm{N}_{2}$ selectivity at $650{ }^{\circ} \mathrm{C}$ were $2.5 \times 10^{-7} \mathrm{~mol} \mathrm{~m}^{-2} \mathrm{~s}^{-1} \mathrm{~Pa}^{-1}$ and 980 , respectively. The original purpose of the addition of ATSB was to improve the hydrothermal stability (described later), but the $\mathrm{H}_{2}$ permeance was also improved compared to the TEOS-derived membranes.

To further improve the $\mathrm{H}_{2}$ permeance, the silica precursor was changed from TEOS to DMDMOS. Figure $6 \mathrm{~d}$ shows the results for the membrane prepared by counter diffusion CVD of DMDMOS and $\mathrm{O}_{2}$. In this case, the membrane fabrication was mostly finished within the first 15 min. After that, the $\mathrm{H}_{2}$ permeance became almost constant, whereas the $\mathrm{N}_{2}$ permeance still decreased slowly, probably because of the modification of some small remaining pores. It is evident that thermal decomposition of DMDMOS was almost negligible, and it actually needed the presence of $\mathrm{O}_{2}$ to form a $\mathrm{SiO}_{2}$ film. After $60 \mathrm{~min}$ of $\mathrm{CVD}$, the $\mathrm{H}_{2}$ permeance and the $\mathrm{H}_{2} / \mathrm{N}_{2}$ selectivity at $500{ }^{\circ} \mathrm{C}$ were $3.3 \times 10^{-7}$ mol $\mathrm{m}^{-2} \mathrm{~s}^{-1} \mathrm{~Pa}^{-1}$ and 82, respectively. Considering the fact that the measurement was taken at $500{ }^{\circ} \mathrm{C}$, the $\mathrm{H}_{2}$ permeance was already much higher than that for a TEOS-derived membrane, but it was not as high as the literature value $\left(9.0 \times 10^{-7} \mathrm{~mol} \mathrm{~m}^{-2} \mathrm{~s}^{-1} \mathrm{~Pa}^{-1}\right)$ [17]. Figure 6e shows the results for the membrane prepared by one-sided diffusion CVD of DMDMOS and $\mathrm{O}_{2}$. After $45 \mathrm{~min}$ of CVD, the $\mathrm{H}_{2}$ permeance and the $\mathrm{H}_{2} / \mathrm{N}_{2}$ selectivity at $500{ }^{\circ} \mathrm{C}$ were $3.8 \times 10^{-7} \mathrm{~mol} \mathrm{~m}^{-2} \mathrm{~s}^{-1} \mathrm{~Pa}^{-1}$ and 90 , respectively. Finally, Figure $6 \mathrm{f}$ shows the results of the membrane prepared by one-sided diffusion CVD of DMDMOS/ATSB/O 2 . After 45 min of CVD, the $\mathrm{H}_{2}$ permeance and the $\mathrm{H}_{2} / \mathrm{N}_{2}$ selectivity at $500{ }^{\circ} \mathrm{C}$ were $4.0 \times 10^{-7} \mathrm{~mol} \mathrm{~m}^{-2} \mathrm{~s}^{-1} \mathrm{~Pa}^{-1}$ and 130 , respectively.

Overall, the $\mathrm{H}_{2}$ permeances of the DMDMOS-derived membranes were not as high as that reported in the literature $\left(9.0 \times 10^{-7} \mathrm{~mol} \mathrm{~m}^{-2} \mathrm{~s}^{-1} \mathrm{~Pa}^{-1}\right)$ [17], probably due to the lack of optimization of the CVD parameters. However, the permeance measurements for several gas species (Figure 7a) revealed that the DMDMOS-derived membrane may have a looser silica network compared to the TEOS-derived membranes. The first evidence for this inference is that the $\mathrm{He} / \mathrm{H}_{2}$ permeance ratio for the fresh DMDMOS membrane was as low as 1.2. The value was much lower than those for TEOS-derived membranes (usually $>2.0$ ), suggesting that the average pore size of the DMDMOS-derived silica network was significantly larger than the kinetic diameters of $\mathrm{H}_{2}(0.289 \mathrm{~nm})$ or $\mathrm{He}(0.26 \mathrm{~nm})$. In fact, the $\mathrm{H}_{2}$ permeance was higher than that for a TEOS-derived membrane, but the He permeance was lower. 


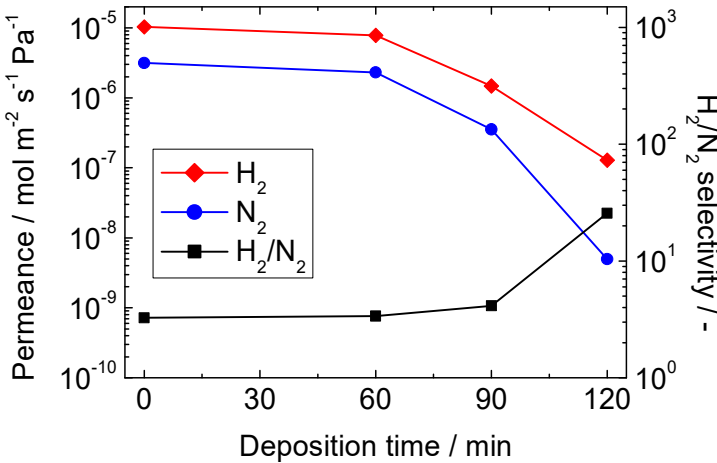

(a) Change in gas permeances with deposition time for a membrane prepared by one-sided diffusion CVD of pure TEOS

(dip-coating: $40 \mathrm{~nm}$ sol only)

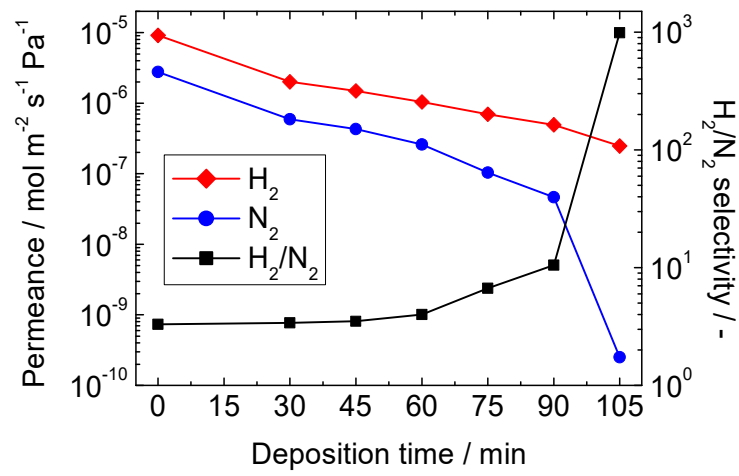

(c) Change in gas permeances with deposition time for a membrane prepared by one-sided diffusion CVD of TEOS/ATSB

(dip-coating: $80 \mathrm{~nm}$ sol and $40 \mathrm{~nm} \mathrm{sol}$ )

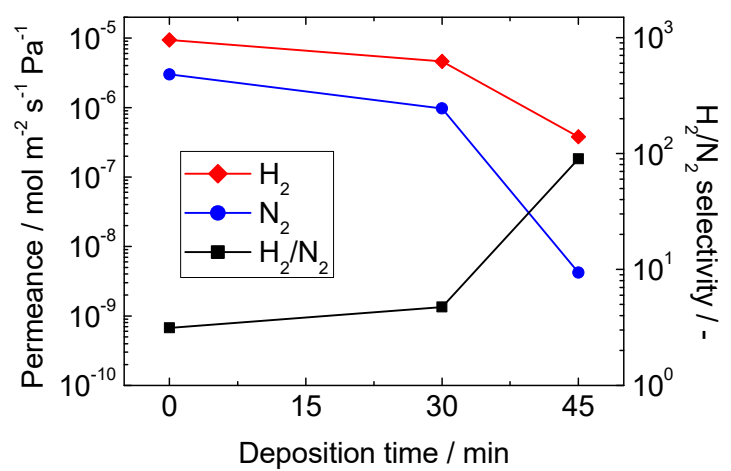

(e) Change in gas permeances with deposition time for a membrane prepared by one-sided diffusion CVD of DMDMOS/O2

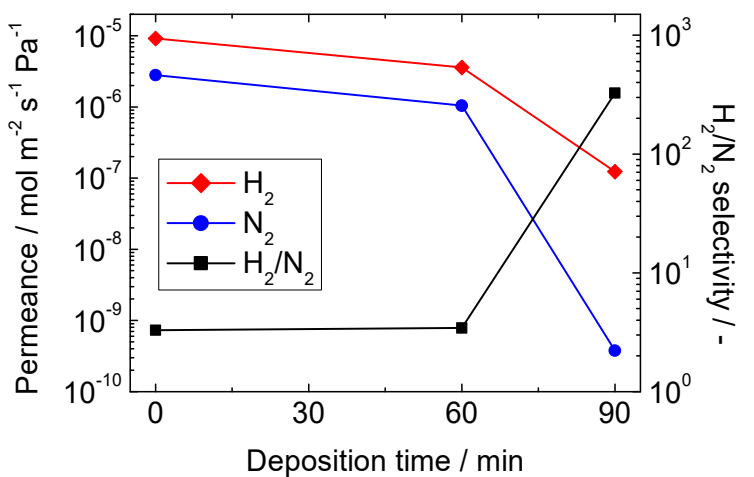

(b) Change in gas permeances with deposition time for a membrane prepared by one-sided diffusion CVD of pure TEOS

(dip-coating: $80 \mathrm{~nm}$ sol and $40 \mathrm{~nm} \mathrm{sol}$ )

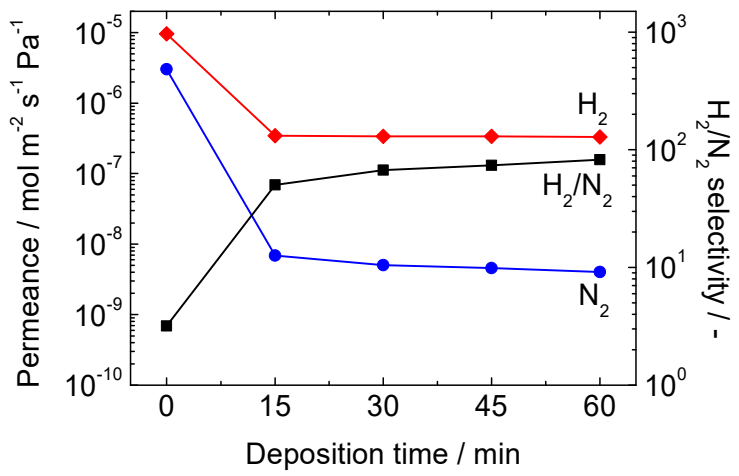

(d) Change in gas permeances with deposition time for a membrane prepared by counter diffusion CVD of DMDMOS/O $/ \mathrm{O}_{2}$

(dip-coating: $80 \mathrm{~nm} \mathrm{sol} \mathrm{and} 40 \mathrm{~nm} \mathrm{sol}$ )

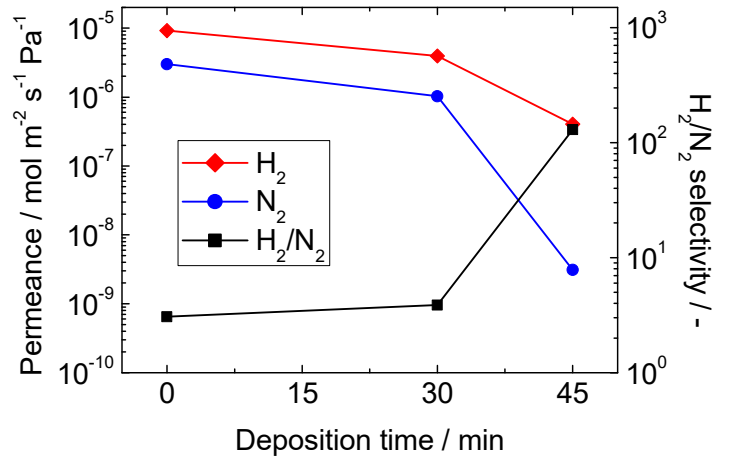

(f) Change in gas permeances with deposition time for a membrane prepared by one-sided diffusion CVD of DMDMOS/ATSB $/ \mathrm{O}_{2}$

(dip-coating: $80 \mathrm{~nm}$ sol and $40 \mathrm{~nm} \mathrm{sol}$ )

Figure 6. Change in gas permeances with deposition time for various types of membranes.

The data for the different gases (Figure 7a) can be analyzed by a normalized Knudsen-based permeance method [20]. The method is derived from the gas translation model. First, the gas permeances of the various gases with different kinetic diameters were converted to normalized 
Knudsen permeances using Equation (5). The obtained results were then plotted as a function of molecular size (Figure 7b). Finally, Equation (6) was used to fit the experimental data, using $d_{p}$ as fitting parameter.

$$
\begin{gathered}
f=\frac{\overline{P_{i}}}{\bar{P}_{H e} \sqrt{\frac{M_{H e}}{M_{i}}}} \\
f=\frac{\left(1-\frac{d_{i}}{d_{p}}\right)^{3}}{\left(1-\frac{d_{H e}}{d_{p}}\right)^{3}}
\end{gathered}
$$

In these equations, where $f$ represents the ratio of the permeance of the $i$-th component $\left(\overline{P_{i}}\right)$ to that predicted from a reference component $(\mathrm{He})$ based on the Knudsen diffusion mechanism, $d_{i}$ is the kinetic diameter of gas $i(\mathrm{~nm}), d_{\mathrm{He}}$ is the kinetic diameter of helium and $d_{p}$ is the estimated membrane pore size (nm). $\bar{P}_{H e} \sqrt{\frac{M_{H e}}{M_{i}}}$ is the permeance of the $i$-th component predicted from the He permeance under the Knudsen diffusion mechanism. $M_{H e}$ and $M_{i}$ are the molecular weight of helium and gas $i$, respectively $\left(\mathrm{g} \mathrm{mol}^{-1}\right)$. The analysis gives a pore size of $0.39 \mathrm{~nm}$ (Figure $7 \mathrm{~b}$ ). A comparable pure $\mathrm{SiO}_{2}$ membrane derived from TEOS gives a pore size of $0.34 \mathrm{~nm}$ [53] to $0.37 \mathrm{~nm}$ [60], confirming that the structure of the DMDMOS-derived membrane is looser.

(a)

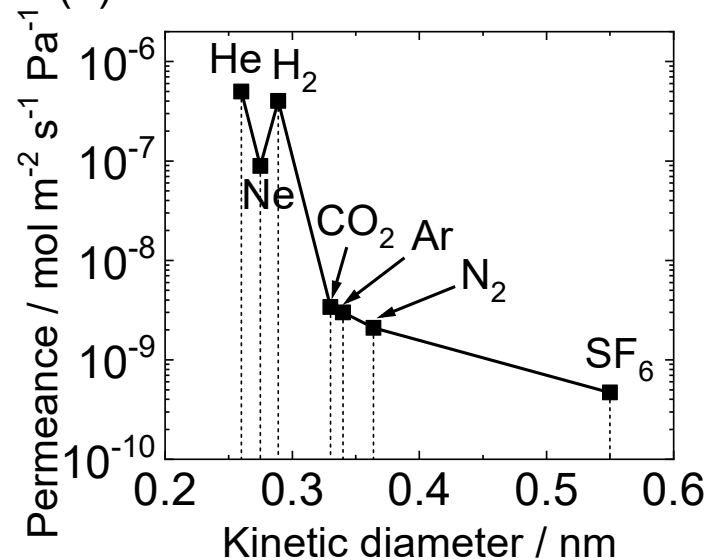

(b)

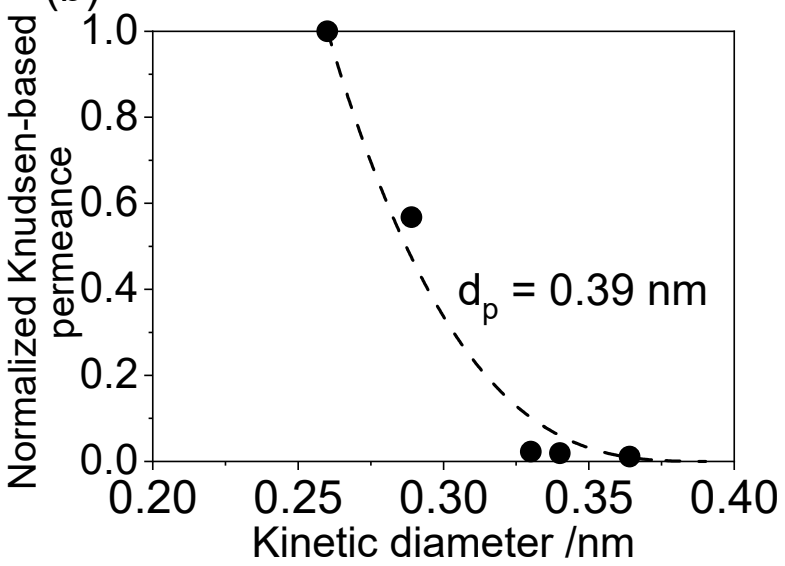

Figure 7. (a) Gas permeances for a membrane synthesized by counter-diffusion CVD of DMDMOS and $\mathrm{O}_{2}$ measured at $650{ }^{\circ} \mathrm{C}$ (before hydrothermal treatment), (b) determination of pore size.

The second evidence for the more open structure of the DMDMOS-derived membrane over a pure TEOS-derived membrane is that the permeance order of $\mathrm{CO}_{2}, \mathrm{Ar}$, and $\mathrm{N}_{2}$ followed the order of their molecular size rather than their molecular weight. This behavior can hardly be observed for a TEOS-derived membrane, where larger gas molecules permeate through defects in the membrane by the Knudsen mechanism, thereby resulting in a permeance order dominated by their molecular weight. The molecular sieving effect for $\mathrm{CO}_{2}, \mathrm{Ar}$, and $\mathrm{N}_{2}$ strongly suggests that there actually were some micropores present which allowed their passage. Furthermore, although the permeances of the above three gas species were on the order of $10^{-9} \mathrm{~mol} \mathrm{~m}^{-2} \mathrm{~s}^{-1} \mathrm{~Pa}^{-1}$, the permeance of $\mathrm{SF}_{6}$ was on the order of $10^{-10} \mathrm{~mol} \mathrm{~m}^{-2} \mathrm{~s}^{-1} \mathrm{~Pa}^{-1}$. This indicated that the membrane had few defects such as pinholes or cracks, and that $\mathrm{CO}_{2}, \mathrm{Ar}$, and $\mathrm{N}_{2}$ permeated through the membrane mainly by the molecular sieving mechanism, and the contribution of the Knudsen permeation was not important. Considering the above findings, there would be a chance to further improve the $\mathrm{H}_{2}$ permeance of the DMDMOS membranes by minimizing the membrane thickness through the optimization of the CVD parameters. 


\subsection{Hydrothermal Stability of the Membranes}

First, a long-term hydrothermal stability test was conducted for both the inside and outside of the membrane tube using a membrane prepared from TEOS and ATSB. The result is shown in Figure 8. When the inner tube was exposed to $16 \mathrm{~mol} \%$ water vapor, the $\mathrm{H}_{2}$ permeance was rapidly lost for the first $12 \mathrm{~h}$, and then became somewhat stabilized after $96 \mathrm{~h}$ of exposure. The tendency was quite normal, and the loss of permeance was much smaller than that for pure silica membranes. The $\mathrm{N}_{2}$ permeance remained almost unchanged. Next, the configuration of the apparatus was altered and the outer shell was exposed to $16 \mathrm{~mol} \%$ water vapor. The original purpose of this treatment was to examine the degree of pinhole enlargement caused by the deterioration of $\gamma$-alumina.

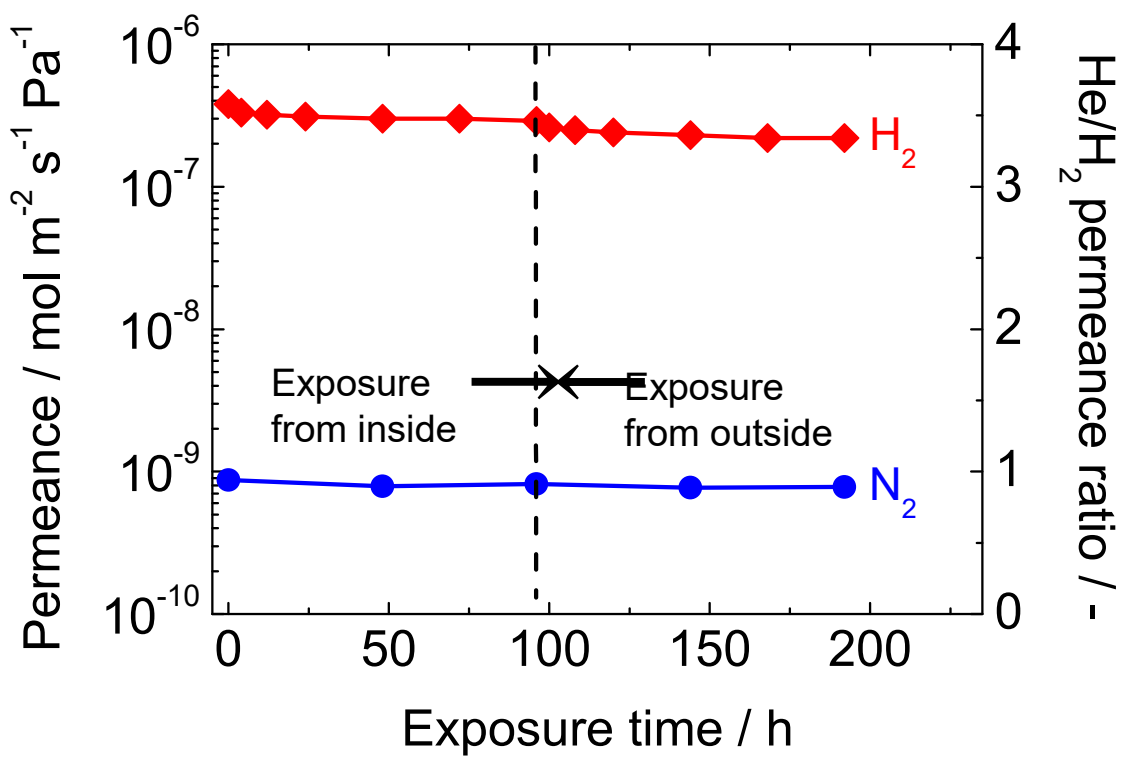

Figure 8. Results of the long-term hydrothermal stability tests to both the inside and outside of the membrane tube.

However, unlike the case of membranes prepared by counter-diffusion CVD [41,49], there was no remarkable change in the $\mathrm{N}_{2}$ permeance. This was probably due to the structural difference between the membranes prepared by counter-diffusion CVD and one-sided diffusion CVD. In the former case, the silica film is generally deposited within the pores of $\gamma$-alumina, thus the continuity of the silica might be susceptive to the structural change of $\gamma$-alumina. In the latter case, a thin silica "layer" is deposited on top of the $\gamma$-alumina layer, so pinholes can hardly be created even if the average Kelvin pore diameter of $\gamma$-alumina increases by the hydrothermal exposure. Rather than a change of the $\mathrm{N}_{2}$ permeance, a sharp decrease of the $\mathrm{H}_{2}$ permeance was observed again for the first $12 \mathrm{~h}$ of exposure. This was probably because of the attack of the $\mathrm{H}_{2} \mathrm{O}$ molecules on both sides of the silica layer, as shown in Figure 9.

Although the reported kinetic diameter of $\mathrm{H}_{2} \mathrm{O}$ has some variation in the literature $(0.265 \mathrm{~nm}$ [32], $0.2995 \mathrm{~nm}$ and $0.314 \mathrm{~nm}$ [61]), the $\mathrm{H}_{2} \mathrm{O}$ permeance is expected to be more than two magnitudes lower than the $\mathrm{H}_{2}$ permeance according to the literature [57]. Therefore, it is likely that only the silica network near the surface underwent densification during the first hydrothermal treatment to the inner tube. Then, the silica network near the intersection between the silica and $\gamma$-alumina underwent densification during the treatment of the outer shell. Another remarkable finding was that the $\mathrm{He} / \mathrm{H}_{2}$ permeance ratio tended to increase by exposure to hydrothermal conditions, which has also been pointed out in the literature [41]. This is also indicative of the densification of the silica layer. The kinetic diameters of $\mathrm{He}$ and $\mathrm{H}_{2}$ are 0.26 and $0.289 \mathrm{~nm}$ respectively, whereas the pore size of the TEOS-derived membrane right after synthesis is roughly estimated to be $0.3 \mathrm{~nm}$. As the densification proceeds, the pore size and the $\mathrm{H}_{2}$ molecular size will become extremely close to each other, but there still will be a relatively 
large difference between the pore size and the He molecular size. This is why the reduction in the He permeance was not as sharp as that in the $\mathrm{H}_{2}$ permeance.
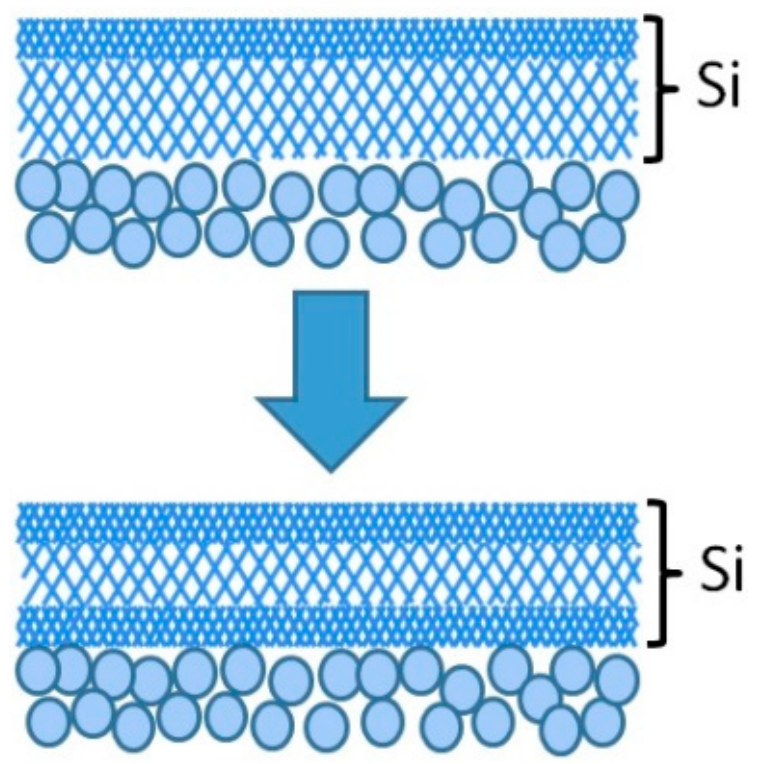

Figure 9. Proposed mechanism for the sharp decrease of the $\mathrm{H}_{2}$ permeance, which was observed twice.

Next, a hydrothermal stability test was conducted for a pure silica membrane synthesized from DMDMOS, and the result is shown in Figure 10. It was revealed that, although the DMDMOS-derived membrane had better initial performance than a TEOS-derived membrane, it had extremely poor hydrothermal stability and could not maintain its superior performance over a long period of time. The $\mathrm{H}_{2}$ permeance before the hydrothermal exposure was $3.2 \times 10^{-7} \mathrm{~mol} \mathrm{~m}^{-2} \mathrm{~s}^{-1} \mathrm{~Pa}^{-1}$ at $650{ }^{\circ} \mathrm{C}$, and it was reduced by about $75 \%$, and that after $192 \mathrm{~h}$ of exposure was $7.8 \times 10^{-8} \mathrm{~mol} \mathrm{~m}^{-2} \mathrm{~s}^{-1} \mathrm{~Pa}^{-1}$. Another remarkable finding was that the $\mathrm{N}_{2}$ permeance also underwent a very large drop from the order of $10^{-9} \mathrm{~mol} \mathrm{~m}^{-2} \mathrm{~s}^{-1} \mathrm{~Pa}^{-1}$ to $10^{-10} \mathrm{~mol} \mathrm{~m}^{-2} \mathrm{~s}^{-1} \mathrm{~Pa}^{-1}$ by the hydrothermal exposure. This strongly suggests that the micropores through which $\mathrm{N}_{2}$ could permeate had shrunk into much smaller micropores that no longer allowed the permeation of $\mathrm{N}_{2}$.

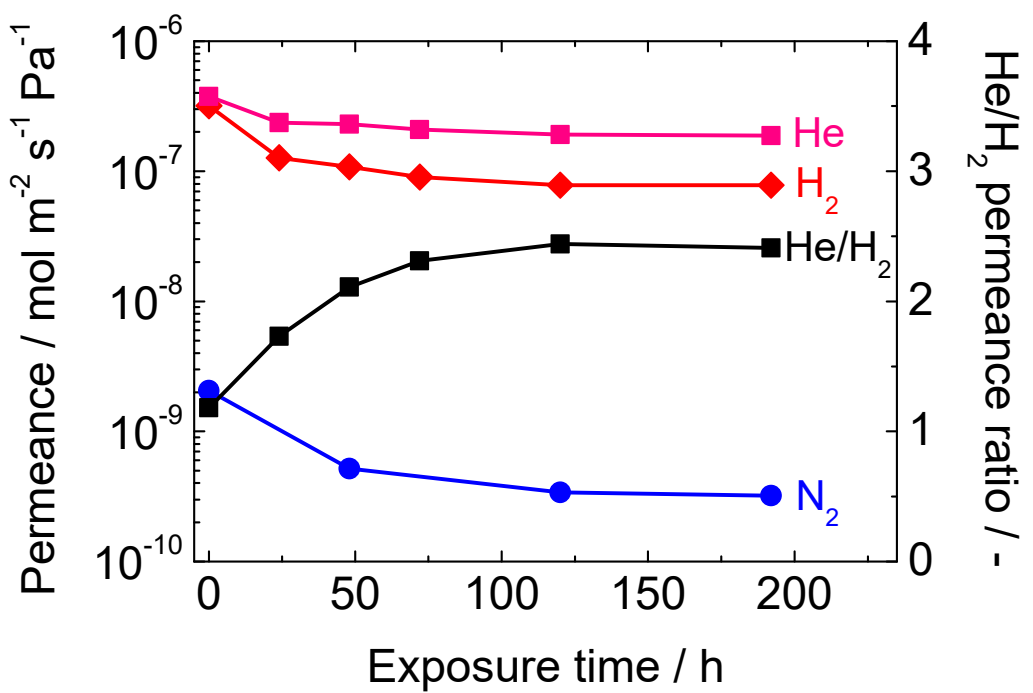

Figure 10. Results of the hydrothermal stability test for a pure silica membrane synthesized from DMDMOS. 
To obtain a deeper understanding of the gas permeation mechanism of this new membrane, the temperature dependence of the gas permeances after the hydrothermal treatment was investigated and the result is shown in Figure 11. The gas permeation behavior after the densification was quite similar to that for a TEOS-derived membrane, probably because the average pore size of the silica layer became about $0.3 \mathrm{~nm}$ or smaller by the hydrothermal exposure. It is remarkable that, although the permeance of $\mathrm{CO}_{2}$ was higher than that of $\mathrm{N}_{2}$ before the exposure, their permeance order became reversed after the exposure, indicating that the permeation mechanism changed from molecular sieve to Knudsen. In any case, a membrane with $\mathrm{H}_{2}$ permeance on the order of $10^{-8} \mathrm{~mol} \mathrm{~m}^{-2} \mathrm{~s}^{-1} \mathrm{~Pa}^{-1}$ is not attractive for membrane reactor applications as a minimum permeance of $10^{-7} \mathrm{~mol} \mathrm{~m}^{-2} \mathrm{~s}^{-1} \mathrm{~Pa}^{-1}$ is needed [40], and therefore, improvement was necessary.

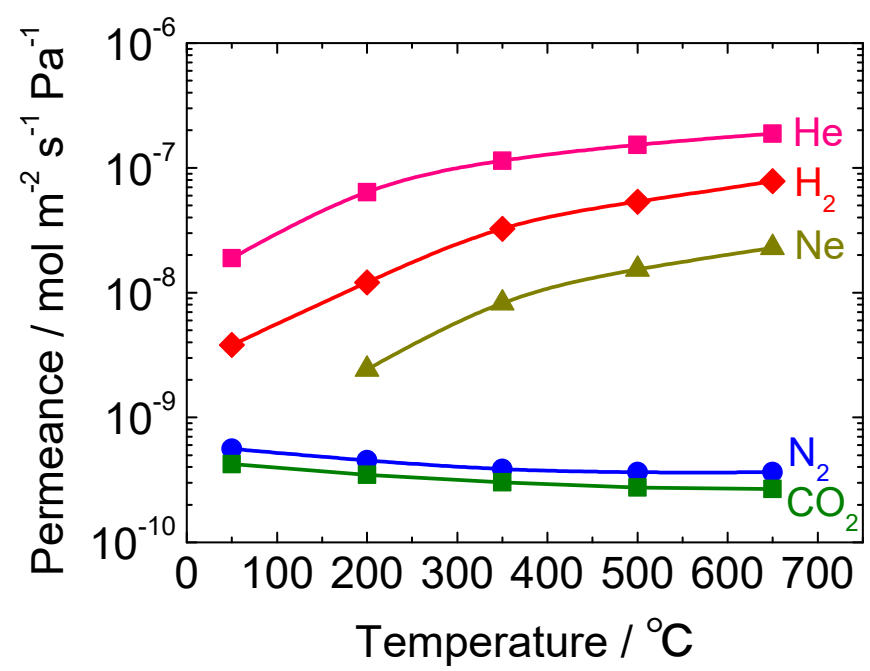

Figure 11. Temperature dependence of the gas permeances after the hydrothermal treatment for a pure silica membrane synthesized from DMDMOS.

Then, a hydrothermal stability test was conducted for a silica-alumina composite membrane synthesized by the one-sided diffusion CVD of DMDMOS/ATSB/O 2 , and the result is shown in Figure 12. It can be seen that the hydrothermal stability of the membrane was significantly improved. The initial $\mathrm{H}_{2}$ permeance was $4.0 \times 10^{-7} \mathrm{~mol} \mathrm{~m}^{-2} \mathrm{~s}^{-1} \mathrm{~Pa}^{-1}$, and that after $94 \mathrm{~h}$ of exposure became $2.5 \times 10^{-7} \mathrm{~mol} \mathrm{~m}^{-2} \mathrm{~s}^{-1} \mathrm{~Pa}^{-1}$. The reduction was only $38 \%$ in this case. This new membrane was used for the membrane reactor studies on the ethane dehydrogenation reaction in a forthcoming study.

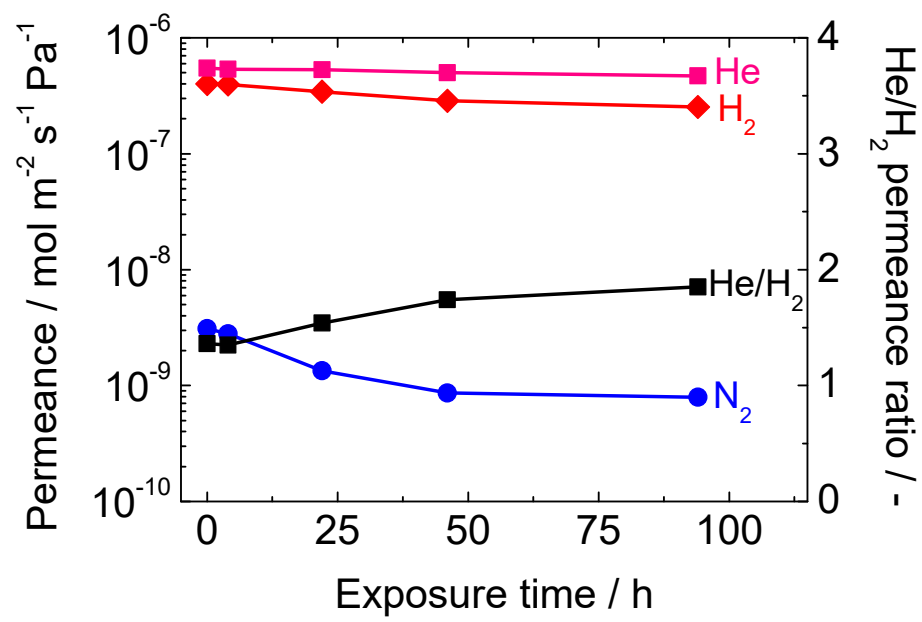

Figure 12. Result of the hydrothermal stability test for a silica-alumina composite membrane synthesized by one-side diffusion CVD of DMDMOS/ATSB/O 2 . 
In order to make a comparison, surface SEM pictures after the long-term hydrothermal stability tests were taken for both a defect-free membrane and a deteriorated membrane. Figure 13a shows the surface of a membrane which still had $\mathrm{H}_{2} / \mathrm{N}_{2}$ selectivity above 100 . Although the silica surface shows a granular morphology compared to that of a fresh surface (Figure $5 d$ ), the $\gamma$-alumina was still completely covered by a continuous silica layer. On the other hand, Figure 13b shows the surface of a different membrane which had $\mathrm{H}_{2} / \mathrm{N}_{2}$ selectivity of around only 10 after the hydrothermal exposure. There are many clearly visible pinhole defects, through which larger gas molecules such as $\mathrm{N}_{2}$ or $\mathrm{CO}_{2}$ could permeate by Knudsen diffusion.

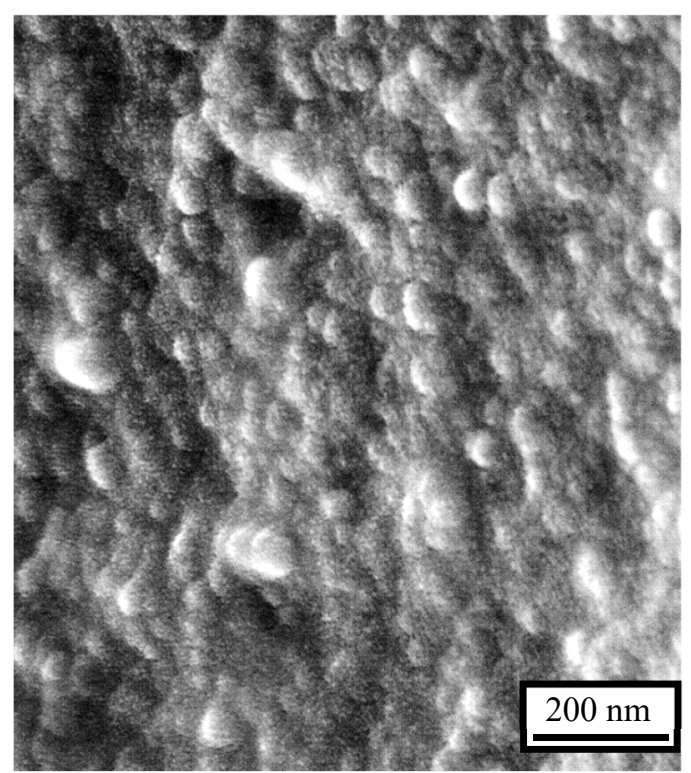

(a) Surface of the topmost Si-Al composite layer after hydrothermal treatment (membrane with final $\mathrm{H}_{2} / \mathrm{N}_{2}$ selectivity $>100$ )

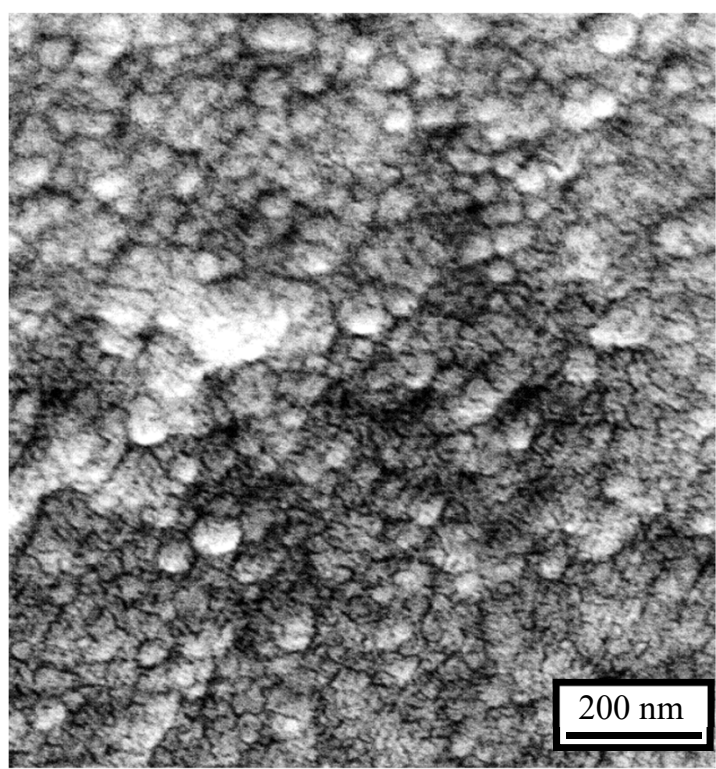

(b) Surface of the topmost Si-Al composite layer after hydrothermal treatment (different membrane with final $\mathrm{H}_{2} / \mathrm{N}_{2}$ selectivity $\sim 10$ )

Figure 13. SEM images of the membrane surface after the long-term hydrothermal treatment.

Figure 14 shows a summary of the performance of a total number of 16 membranes fabricated in this study, the intermediate layers of which were synthesized by the sequential treatment with an 80 and a $40 \mathrm{~nm}$ sol. Even though the synthesis steps were simplified compared to a previous study [35], Si-Al composite membranes with $\mathrm{H}_{2}$ permeance $>1.5 \times 10^{-7} \mathrm{~mol} \mathrm{~m}^{-2} \mathrm{~s}^{-1} \mathrm{~Pa}^{-1}$ and $\mathrm{H}_{2} / \mathrm{N}_{2}$ selectivity $>$ 100 have been successfully fabricated many times, demonstrating the level of reproducibility of the membrane fabrication process used in this study. There are many steps that enter into the synthesis, including joining of the support to the dense alumina tubes, the preparation of the sols, the dip-coating procedure, and the CVD process, and it is difficult to control all the steps. Nevertheless, the results are significant as the values of $\mathrm{H}_{2}$ permeance $>1.5 \times 10^{-7} \mathrm{~mol} \mathrm{~m}^{-2} \mathrm{~s}^{-1} \mathrm{~Pa}^{-1}$ and $\mathrm{H}_{2} / \mathrm{N}_{2}$ selectivity $>100$ noted above were shown to be requirements for a commercial process [36]. This involved the study of the model $\mathrm{A} \rightarrow \mathrm{B}+\mathrm{C}$ reaction, the dihydrogen-ation of ethane $\left(\mathrm{C}_{2} \mathrm{H}_{6} \rightarrow \mathrm{C}_{2} \mathrm{H}_{4}+\mathrm{H}_{2}\right)$ over a $5 \mathrm{wt} \% \mathrm{Cr} / \mathrm{ZSM}-5$ catalyst in a conventional packed-bed reactor (PBR) and in a membrane reactor (MR) fitted with hydrogen-selective silica membranes. Specifically, it was demonstrated that for the all-important permeance range of $10^{-7}$ and $10^{-6} \mathrm{~mol} \mathrm{~m}^{-2} \mathrm{~s}^{-1} \mathrm{~Pa}^{-1}$, there was an enhancement in yield as $\mathrm{H}_{2}$ selectivity increased from 10 to 20 and 30, but beyond 100, there was little improvement even with a selectivity of 1000 [36]. Thus, a selectivity of 100 is sufficient for most applications involving membrane reactors.

It should be noted, however, that the membrane performance (especially the $\mathrm{H}_{2}$ permeance) tended to be reduced after the long-term hydrothermal treatment, and it was not easy to maintain the above-mentioned performance over a long period of time. It was also remarkable that, when the 
initial $\mathrm{H}_{2} / \mathrm{N}_{2}$ selectivity was lower than 100 , the membrane performance tended to deteriorate by the hydrothermal treatment, probably because of fatal pinhole enlargement. This provides a direction for improvement, that is the number of defects should be reduced at the outset.

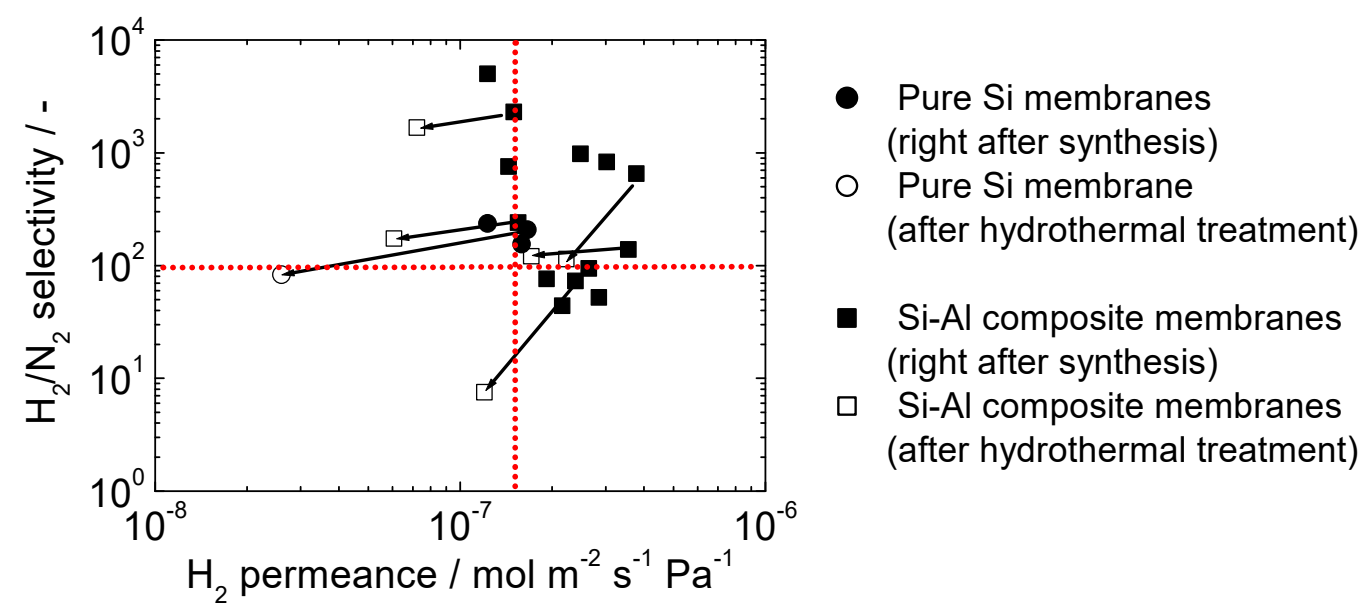

Figure 14. Summary of the performance of a total number of 16 membranes synthesized from TEOS or TEOS + ATSB.

\section{Conclusions}

Silica-alumina composite membranes with $\mathrm{H}_{2}$ permeance $>1.5 \times 10^{-7} \mathrm{~mol} \mathrm{~m}^{-2} \mathrm{~s}^{-1} \mathrm{~Pa}^{-1}$ and $\mathrm{H}_{2} / \mathrm{N}_{2}$ selectivity $>100$ have been successfully fabricated repeatedly, even though the membrane fabrication steps were simplified compared to previous studies. In addition, the use of a novel silica precursor, dimethyl dimethoxy silane (DMDMOS), further improved the $\mathrm{H}_{2}$ permeance without compromising the $\mathrm{H}_{2}$ selectivity. Even though the pure silica membranes synthesized from DMDMOS had poor hydrothermal stability just like the TEOS-derived membranes, the addition of aluminum tri-sec-butoxide (ATSB) rendered the membrane much more stable.

Author Contributions: H.A. carried out the research and wrote the initial draft, A.T. and R.K. helped to direct the research and analyze the results, T.S. helped with the scanning electron microscopy, S.T.O. planned the work, obtained the funding, and edited the manuscript. All authors have read and agreed to the published version of the manuscript.

Funding: This work was supported by the Japan Science and Technology Agency under the CREST program, Grant Number JPMJCR16P2.

Conflicts of Interest: The authors declare no conflict of interest.

\section{References}

1. Gallucci, F.; Fernandez, E.; Corengia, P.; van Sint Annaland, M. Review Recent advances on membranes and membrane reactors for hydrogen production. Chem. Eng. Sci. 2013, 92, 40-66. [CrossRef]

2. Khatib, S.J.; Oyama, S.T. Review of silica membranes for hydrogen separation prepared by CVD. Sep. Purif. Technol. 2013, 111, 20-42. [CrossRef]

3. Khatib, S.J.; Oyama, S.T.; de Souza, K.R.; Noronha, F.B. Review of silica membranes for hydrogen separation prepared by chemical vapor deposition. In Inorganic, Polymeric and Composite Membranes, Structure, Function and Correlations, Membrane Science and Technology Series; Oyama, S.T., Stagg-Williams, S.M., Eds.; Elsevier Science: Amsterdam, The Netherlands, 2011; Volume 14, p. 25.

4. Ten Hove, M.; Luiten-Olieman, M.W.J.; Huiskes, C.; Nijmeijer, A.; Winnubst, L. Hydrothermal stability of silica, hybrid silica and Zr-doped hybrid silica membranes. Sep. Purif. Technol. 2017, 189, 48-53. [CrossRef]

5. Akamatsu, K.; Tago, T.; Seshimo, M.; Nakao, S.-I. Long-term stable $\mathrm{H}_{2}$ production from methylcyclohexane using a membrane reactor with a dimethoxydiphenylsilane-derived silica membrane prepared via chemical vapor deposition. Ind. Eng. Chem. Res. 2015, 54, 3996-4000. [CrossRef] 
6. Nagasawa, H.; Minamizawa, T.; Kanezashi, M.; Yoshioka, T.; Tsuru, T. Microporous organosilica membranes for gas separation prepared via PECVD using different O/Si ratio precursors. J. Membr. Sci. 2015, 489, 11-19. [CrossRef]

7. Gao, X.; Diniz da Costa, J.C.; Bhatia, S.K. Adsorption and transport of gases in a supported microporous silica membrane. J. Membr. Sci. 2015, 460, 46-61. [CrossRef]

8. Yin, Y.; Xua, T.; Shen, X.; Wu, H.; Jiang, Z. Fabrication of chitosan/zwitterion functionalized titania-silica hybrid membranes with improved proton conductivity. J. Membr. Sci. 2014, 469, 355-363. [CrossRef]

9. Okubo, T.; Inoue, H. Introduction of specific gas reactivity to porous glass membranes by treatment with tetraethoxysilane. J. Membr. Sci. 1989, 42, 109-119. [CrossRef]

10. Gavalas, G.R.; Megiris, C.E.; Nam, S.W. Deposition of $\mathrm{H}_{2}$-permselective $\mathrm{SiO}_{2}$ films. Chem. Eng. Sci. 1989, 44, 1829-1839. [CrossRef]

11. De Lange, R.S.A.; Keizer, K.; Burggraaf, A.J. Analysis and theory of gas transport in microporous sol-gel derived ceramic membranes. J. Membr. Sci. 1995, 104, 81-91. [CrossRef]

12. Okubo, T.; Haruta, K.; Kusakabe, K.; Morooka, S.; Anzai, H.; Akiyama, S. Preparation of sol-gel derived thin membrane on a porous ceramic hollow filter by the filtration technique. J. Membr. Sci. 1991, 59, 73-83. [CrossRef]

13. Nam, S.W.; Ha, H.Y.; Yoon, S.P.; Han, J.; Lim, T.H.; Oh, I.H.; Hong, S.A. Hydrogen-permselective $\mathrm{TiO}_{2} / \mathrm{SiO}_{2}$ membranes formed by chemical vapor deposition. Korean Membr. J. 2001, 3, 69-78.

14. Megiris, C.E.; Glezer, J.H.E. Permeation of silicon dioxide films by low-pressure chemical vapor deposition on dense and porous alumina substrates. Chem. Eng. Sci. 1992, 47, 3925-3933. [CrossRef]

15. Ngamou, P.; Overbeek, J.; Kreiter, R.; van Veen, H.; Vente, J.; Wienk, I.; Cuperus, P.; Creatore, M. Plasma deposited hybrid silica membranes with a controlled retention of organic bridges. J. Mater. Chem. A 2013, 1, 5567-5576. [CrossRef]

16. Walkiewicz-Pietrzykowska, A.; Cotrino, J.; Gonzalez-Elipe, A.R. Deposition of thin films of $\mathrm{SiO}_{\mathrm{x}} \mathrm{C}_{\mathrm{y}} \mathrm{H}$ in a surfatron microwave plasma reactor with hexamethyldisiloxane as precursor. Chem. Vap. Depos. 2005, 11, 317-323. [CrossRef]

17. Nomura, M. Stability of $\mathrm{H}_{2}$-permselective $\mathrm{SiO}_{2}$ films formed by chemical vapor deposition. Membrane 2007, 32, 340-346. [CrossRef]

18. Zhang, X.; Yamada, H.; Saito, T.; Kai, T.; Murakami, K.; Nakashima, M.; Ohshita, J.; Akamatsu, K.; Nakao, S. Development of hydrogen-selective triphenylmethoxysilane-derived silica membranes with tailored pore size by chemical vapor deposition. J. Membr. Sci. 2016, 499, 28-35. [CrossRef]

19. Niimi, T.; Nagasawa, H.; Kanezashi, M.; Yoshioka, T.; Ito, K.; Tsuru, T. Preparation of BTESE-derived organosilica membranes for catalytic membrane reactors of methylcyclohexane dehydrogenation. J. Membr. Sci. 2014, 455, 375-383. [CrossRef]

20. Lee, H.R.; Kanezashi, M.; Shimomura, Y.; Yoshioka, T.; Tsuru, T. Evaluation and fabrication of pore-size-tuned silica membranes with tetraethoxydimethyl disiloxane for gas separation. AIChE J. 2011, 57, 2755-2765. [CrossRef]

21. Yamaguchi, T.; Ying, X.; Tokimasa, Y.; Nair, B.N.; Sugawara, T.; Nakao, S.I. Reaction control of tetraethylorthosilicate (TEOS) $/ \mathrm{O}_{3}$ and tetramethylorthosilicate (TMOS) $/ \mathrm{O}_{3}$ counter diffusuin chemical vapour deposition for preparation of molecular-sieve membranes. Phys. Chem. Chem. Phys. 2000, 2, 4465-4475. [CrossRef]

22. Kageyama, N.; Sugawara, T.; Takagaki, A.; Kikuchi, R.; Oyama, S.T. Overcoming pressure drop losses in membrane reactors by semi-batch operation. Sep. Purif. Tech. 2017, 185, 175-185. [CrossRef]

23. Hekkink, J.H.A.; de Lange, R.S.A.; Ten Hoeve, A.A.; Blankenvoorde, P.J.A.M.; Keizer, K.; Burggraaf, A.J. Characterization and permeation properties of binary $\mathrm{SiO}_{2}-\mathrm{TiO}_{2}$ and $\mathrm{SiO}_{2}-\mathrm{Al}_{2} \mathrm{O}_{3}$ modified gamma-alumina membranes. Key Eng. Mater. 1991, 61, 375-378.

24. Yoshida, K.; Hirano, Y.; Fujii, H.; Tsuru, T.; Asaeda, M. Hydrothermal stability and performance of silica-zirconia membranes for hydrogen separation in hydrothermal conditions. J. Chem. Eng. Jpn. 2001, 34, 523-531. [CrossRef]

25. Kanezashi, M.; Yada, K.; Yoshioka, T.; Tsuru, T. Organic-inorganic hybrid silica membranes with controlled silica network size: Preparation and gas permeation characteristics. J. Membr. Sci. 2010, 348, 310-318. [CrossRef] 
26. Li, H.; Schygulla, U.; Hoffmann, J.; Nichoff, P.; Haas-Santo, K.; Dittmeyer, R. Experimental and modeling study of gas transport through composite ceramic membranes. Chem. Eng. Sci. 2014, 108, 94-102. [CrossRef]

27. Oyama, S.T.; Lee, D.; Hacarlioglu, P.; Saraf, R.F. Theory of hydrogen permeability in nonporous silica membranes. J. Membr. Sci. 2004, 244, 45-53. [CrossRef]

28. Gu, Y.; Oyama, S.T. Ultrathin, hydrogen-selective silica membranes deposited on alumina-graded structures prepared from size-controlled boehmite sols. J. Membr. Sci. 2007, 306, 216-227. [CrossRef]

29. Mise, Y.; Ahn, S.-J.; Takagaki, A.; Kikuchi, R.; Oyama, S.T. Fabrication and evaluation of trimethylmethoxysilane (TMMOS)-derived membranes for gas separation. Membranes 2019, 9, 123. [CrossRef]

30. Kato, H.; Lundin, S.-T.B.; Ahn, S.-J.; Takagaki, A.; Kikuchi, R.; Oyama, S.T. Gas separation silica membranes prepared by chemical vapor deposition of methyl-substituted silanes. Membranes 2019, 9, 144. [CrossRef]

31. Oyama, S.T.; Yamada, M.; Sugawara, T.; Takagaki, A.; Kikuchi, R. Review on mechanisms of gas permeation through inorganic membranes. J. Jpn. Pet. Inst. 2011, 54, 298-309. [CrossRef]

32. Igi, R.; Kanezashi, M.; Yoshioka, T.; Fujisaki, S.; Iwamoto, Y.; Tsuru, T. Permeation properties of hydrogen and water vapor through porous silica membranes at high temperatures. AIChE J. 2011, 57, 618-629.

33. Kanezashi, M.; Sasaki, T.; Tawarayama, H.; Nagasawa, H.; Yoshioka, T.; Ito, K.; Tsuru, T. Experimental and theoretical study on small gas permeation properties through amorphous silica membranes fabricated at different temperatures. J. Phys. Chem. 2014, 118, 20323-20331. [CrossRef]

34. Okubo, T.; Watanabe, M.; Kusakabe, K.; Morooka, S. Preparation of $\gamma$-alumina thin membrane by sol-gel processing and its characterization by gas permeation. J. Mater. Sci. 1990, 25, 4822-4827. [CrossRef]

35. Gu, Y.; Oyama, S.T. High molecular permeance in a poreless ceramic membrane. Adv. Mater. 2007, 19, 1636-1640. [CrossRef]

36. Ahn, S.J.; Yun, G.N.; Takagaki, A.; Kikuchi, R.; Oyama, S.T. Effects of pressure contact time, permeance, and selectivity in membrane reactors: The case of the dehydrogenation of ethane. Sep. Purif. Technol. 2018, 194, 197-206. [CrossRef]

37. Ma, L.-C.; Castro-Dominguez, B.; Kazantzis, N.K.; Ma, Y.H. A cost assessment study for a large-scale water gas shift catalytic membrane reactor module in the presence of uncertainty. Sep. Purif. Technol. 2016, 166, 205-212. [CrossRef]

38. Meng, L.; Yu, X.; Niimi, T.; Nagasawa, H.; Kanezashi, M.; Yoshioka, T.; Tsuru, T. Methylcyclohexane dehydrogenation for hydrogen production via a bimodal catalytic membrane reactor. AIChE J. 2015, 61, 1628-1638. [CrossRef]

39. Araki, S.; Miyanishi, H.; Yano, H.; Tanaka, S.; Miyake, Y. Water gas shift reaction in a membrane reactor using a high hydrogen permselective silica membrane. Sep. Sci. Technol. 2013, 48, 76-83. [CrossRef]

40. Lim, H.; Gu, Y.; Oyama, S.T. Studies of the effect of pressure and hydrogen permeance on the ethanol steam reforming reaction with palladium- and silica-based membranes. J. Membr. Sci. 2012, 396, 119-127. [CrossRef]

41. Nagano, T.; Sato, K. Degradation mechanism of an $\mathrm{H}_{2}$-permselective amorphous silica membrane. J. Mater. Sci. 2014, 49, 4115-5120. [CrossRef]

42. Nomura, M.; Aida, H.; Gopalakrishnan, S.; Sugawara, T.; Nakao, S.I.; Yamazaki, S.; Inada, T.; Iwamoto, Y. Steam stability of a silica membrane prepared by counter diffusion chemical vapor deposition. Desalination 2006, 193, 1-7. [CrossRef]

43. Lim, H.; Gu, Y.; Oyama, S.T. Reaction of primary and secondary products in a membrane reactor: Studies of ethanol steam reforming with a silica-alumina composite membrane. J. Membr. Sci. 2010, 351, 149-159. [CrossRef]

44. Kageyama, N.; Takagaki, A.; Sugawara, T.; Kikuchi, R.; Oyama, S.T. Synthesis and characterization of a silica-alumina composite membrane and its application in a membrane reactor. Sep. Purif. Technol. 2018, 195, 437-445. [CrossRef]

45. Gu, Y.; Hacarlioglu, P.; Oyama, S.T. Hydrothermally stable silica-alumina composite membranes for hydrogen separation. J. Membr. Sci. 2008, 310, 28-37. [CrossRef]

46. Gu, Y.; Oyama, S.T. Permeation properties and hydrothermal stability of silica-titania membranes supported on porous alumina substrates. J. Membr. Sci. 2009, 345, 267-275. [CrossRef]

47. Sea, B.K.; Soewito, E.; Watanabe, M.; Kusakabe, K.; Morooka, S.; Kim, S.S. Hydrogen recovery from a $\mathrm{H}_{2}-\mathrm{H}_{2} \mathrm{O}-\mathrm{HBr}$ mixture utilizing silica-based membranes at elevated temperatures. 1. Preparation of $\mathrm{H}_{2} \mathrm{O}-$ and $\mathrm{H}_{2}$-selective membranes. Ind. End. Chem. Res. 1998, 37, 2502-2508. [CrossRef] 
48. Akamatsu, K.; Nakane, M.; Sugawara, T.; Nakao, S.I. Performance under thermal and hydrothermal condition of amorphous silica membrane prepared by chemical vapor deposition. AIChE J. 2009, 55, 2197-2203. [CrossRef]

49. Nagano, T.; Sato, K.; Saito, T.; Takahashi, S. Hydrothermal stability of mesoporous Ni-doped $\gamma-\mathrm{Al}_{2} \mathrm{O}_{3}$. J. Ceram. Soc. Jpn. 2009, 117, 832-835. [CrossRef]

50. Ohta, Y.; Akamatsu, K.; Sugawara, T.; Miyoshi, A.; Nakao, S. Development of pore-size-controlled silica membranes for gas separation by chemical vapor deposition. J. Membr. Sci. 2008, 315, 93-99. [CrossRef]

51. Seshimo, M.; Saito, T.; Akamatsu, K.; Segawa, A.; Nakao, S. Influence of toluene vapor on the $\mathrm{H}_{2}$-selective performance of dimethoxy diphenylsilane-derived silica membranes prepared by the chemical vapor deposition method. J. Membr. Sci. 2012, 415-416, 51-56. [CrossRef]

52. Seshimo, M.; Akamatsu, K.; Furuta, S.; Nakao, $\mathrm{S}$. $\mathrm{H}_{2}$ purification durability of dimethoxy diphenylsilane-derived silica membranes with $\mathrm{H}_{2}$-toluene mixtures. Ind. Eng. Chem. Res. 2013, 52, 17257-17262. [CrossRef]

53. Ahn, S.-J.; Yun, G.-N.; Takagaki, A.; Kikuchi, R.; Oyama, S.T. Synthesis and characterization of hydrogen selective silica membrane prepared by chemical vapor deposition of vinyltriethoxysilane. J. Membr. Sci. 2018, 550, 1-8. [CrossRef]

54. Nishida, R.; Tago, T.; Saitoh, T.; Seshimo, M.; Nakao, S.-I. Development of CVD silica membranes having high hydrogen permeance and steam durability and a membrane reactor for a water gas shift reaction. Membranes 2019, 9, 140. [CrossRef] [PubMed]

55. Sawamura, K.-I.; Okamoto, S.; Todokoro, Y. Development of mass production technology of highly permeable nano-porous supports for silica-based separation membranes. Membranes 2019, 9, 103. [CrossRef] [PubMed]

56. Ishii, K.; Ikeda, A.; Takeuchi, T.; Yoshiura, J.; Nomura, M. Silica-based RO membranes for separation of acidic solution. Membranes 2019, 9, 94. [CrossRef] [PubMed]

57. Nomura, M.; Nishi, Y.; Sakanishi, T.; Utsumi, K.; Nakamura, R. Preparation of thin LiSiO membranes by using a CVD method. Energy Procedia 2013, 37, 1012-1019. [CrossRef]

58. Oyama, S.T.; Hacarlioglu, P. The boundary between simple and complex descriptions of membrane reactors: The transition between 1-D and 2-D analysis. J. Membr. Sci 2009, 337, 188-199. [CrossRef]

59. Oyama, S.T.; Lee, D.; Sugiyama, S.; Fukui, K.; Iwasawa, Y. Characterization of a highly selective hydrogen permeable silica membrane. J. Mater. Sci. 2001, 36, 5213-5223. [CrossRef]

60. Belhaj Messaoud, S.; Takagaki, A.; Sugawara, T.; Kikuchi, R.; Oyama, S.T. Alkylamine-silica hybrid membranes for carbon dioxide/methane separation. J. Membr. Sci. 2015, 477, 161-171. [CrossRef]

61. Kanezashi, M.; Sasaki, T.; Tawarayama, H.; Yoshioka, T.; Tsuru, T. Hydrogen permeation properties and hydrothermal stability of sol-gel-derived amorphous silica membranes fabricated at high temperatures. J. Am. Ceram. Soc. 2013, 96, 2950-2957. [CrossRef] 